\title{
吡唑含能离子盐的合成研究进展
}

\author{
李光䂞 $a, b$ 黄海丰*,b,c 杨 军*,b 段红珍*,a \\ $\left({ }^{a}\right.$ 中北大学理学院 太原 030051) \\ ( ${ }^{b}$ 中国科学院上海有机化学研究所 中国科学院能量调控材料重点实验室 上海 200032) \\ ( ${ }^{c}$ 中国科学院绿色过程制造创新研究院 北京 100190)
}

\begin{abstract}
摘要 吡唑环上有三个可修饰的碳位点和一个可修饰的 $\mathrm{NH}$ 位点, 通过对这四个位点的修饰(主要是引入硝基、硝胺基、 氨基、羟基以及形成稠环等)，可设计出种类丰富的吡唑含能化合物．同时，相对于 2,4,6-三硝基甲苯(TNT)、黑索金 $(\mathrm{RDX}) 、$ 奥克托今 $(\mathrm{HMX})$ 等常规含能化合物, 吡唑含能化合物具有氮含量高、生成焓高及感度低等优势. 近年来, 国内 外基于吡唑骨架设计并合成了大量吡唑含能离子盐, 其中很多种化合物表现出高能及钝感等特性. 按单环吡坐含能离 子盐、联环吡唑含能离子盐及稠环吡唑含能离子盐, 分类综述了近年来所报道的吡唑含能离子盐的合成及性能, 并对 该类化合物的应用前景进行了展望.
\end{abstract}

关键词 含能材料; 含能离子盐; 吡唑; 硝胺

\section{Progress in the Synthesis of Energetic Salts Based on Pyrazole}

\author{
Li, Guanglei ${ }^{a, b}$ Huang, Haifeng ${ }^{*, b, c} \quad$ Yang, Jun ${ }^{*, b} \quad$ Duan, Hongzhen ${ }^{*, a}$ \\ $\left({ }^{a}\right.$ School of Science, North University of China, Taiyuan 030051) \\ $\left({ }^{b}\right.$ Key Laboratory of Energy Regulation Materials, Shanghai Institute of Organic Chemistry, \\ Chinese Academy of Sciences, Shanghai 200032) \\ ( ${ }^{c}$ Innovation Academy for Green Manufacture, Chinese Academy of Sciences, Beijing 100190)
}

\begin{abstract}
The pyrazole ring has three modifiable carbon sites and one modifiable NH site. Based on the pyrazole ring, a variety of pyrazole energetic compounds can be designed by the introduction of nitro, nitramino, amino and hydroxyl group and the formation of fused rings. At the same time, compared with conventional energetic compounds such as 2,4,6-trinitrobenzene (TNT), hexahydro-1,3,5-trinitro-triazine (RDX) and 1,3,5,7-tetranitro-1,3,5,7-tetrazocane (HMX), energetic pyrazoles have the advantages of high nitrogen content, high enthalpy of formation and low sensitivities. In recent years, a large number of energetic salts based on pyrazole have been designed and synthesized around the world, including monocyclic energetic salts, bicyclic energetic salts and fused energetic salts based on pyrazole. Many of them exhibit the characteristics of high energy and low sensitivity. The synthesis and properties of recently reported energetic salts based on pyrazole are reviewed, and their applications in the field of energetic materials are prospected.
\end{abstract}

Keywords energetic material; energetic salt; pyrazole; nitramino

含能材料是武器系统实现发射(推进剂)和毁伤(炸 药)的能量来源, 其性能高低直接关系到武器装备的射 程、威力和安全性等性能 ${ }^{[1-2]}$. 随着国防事业的发展, 对 含能材料的要求越来越高, 需要开发能量密度高、热稳 定性好、机械感度低且环境友好的新型含能材料 ${ }^{[3]}$. 从 2,4,6-三硝基甲苯(TNT) 到黑索金(RDX)、奥克托今 (HMX)、六硝基六氮杂异伍兹烷(CL-20), 含能化合物的 密度、能量水平等得到逐步提高 ${ }^{[4]}$ (图 1). 但是, 随着含
能化合物能量水平的提高, 它们的感度也随之增加. 而 含能化合物的高感度会给其生产、运输和使用过程带来 诸多不安全的隐患, 容易造成严重的人员伤亡和经济损 失 ${ }^{[5]}$. 高能量高感度的含能化合物无法满足对安全性能 要求极高的应用场景, 例如航母和战斗机. 因此, 调节 含能材料的能量与感度之间的这一核心矛盾对于含能 材料的发展具有重大意义.

* Corresponding authors. E-mail: hfhuang@sioc.ac.cn; yangj@sioc.ac.cn; duanhz2000@163.com

Received September 8, 2020; revised September 28, 2020; published online November 3, 2020.

Project supported by the Innovation Academy for Green Manufacture, Chinese Academy of Sciences (No. IAGM2020C06).

中国科学院绿色过程制造创新研究院自主部署联合基金(No. IAGM2020C06)资助项目. 
<smiles>Cc1c([N+](=O)[O-])cc([N+](=O)[O-])cc1[N+](=O)[O-]</smiles>

IS = $15 \mathrm{~J}$

$\mathrm{FS}=353 \mathrm{~N}$; $d=1.65 \mathrm{~g} \cdot \mathrm{cm}^{-3}$; $D=7457 \mathrm{~m} \cdot \mathrm{s}^{-1}$

TNT

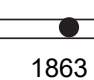<smiles>O=[N+]([O-])N1CN([N+](=O)[O-])CN([N+](=O)[O-])C1</smiles>

IS $=7.5 \mathrm{~J}$;

$\mathrm{FS}=120 \mathrm{~N}$;

$d=1.81 \mathrm{~g} \cdot \mathrm{cm}^{-3}$

$D=8983 \mathrm{~m} \cdot \mathrm{s}^{-1}$<smiles>O=[N+]([O-])N1CN([N+](=O)[O-])CN([N+](=O)[O-])CN([N+](=O)[O-])C1</smiles>

$I S=7 \mathrm{~J}$;

$\mathrm{FS}=112 \mathrm{~N}$; $d=1.90 \mathrm{~g} \cdot \mathrm{cm}^{-3}$; $D=9221 \mathrm{~m} \cdot \mathrm{s}^{-1}$

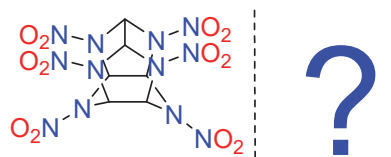

IS $=4 \mathrm{~J}$

$\mathrm{FS}=48 \mathrm{~N}$;

$d=2.04 \mathrm{~g} \cdot \mathrm{cm}^{-3}$

$D=9455 \mathrm{~m} \cdot \mathrm{s}^{-1}$

HMX CL-20

图 1 经典含能化合物

Figure 1 Classical energetic compounds

离子盐类含能化合物很早就被应用于含能材料中, 例如高氯酸铵(AP)被用作固体推进剂的氧化剂的时间 已经超过 60 年 ${ }^{[6]}$, 硝酸铵(AN)被大量应用于工业炸药, 而且其在固体推进剂中的应用也受到了广泛关注 ${ }^{[7-8]}$. 二硝酰胺铵盐 $(\mathrm{ADN})^{[0]}$ 和硝仿肼 $(\mathrm{HNF})^{[10]}$ 被认为是具有 应用前景的固体推进剂高能氧化剂, $\mathrm{ADN}$ 和硝酸着弪胺 (HAN) 被应用于单元液体推进剂 ${ }^{[11]}$ (图 2). 但是, 不难发 现, 这些早期的离子盐类含能化合物均是基于非杂环结 构类阴离子如高氯酸根、硝酸根、二硝酰胺阴离子和硝 仿阴离子, 而且它们的主要用途是用作固体推进剂及液 体推进剂的氧化剂.

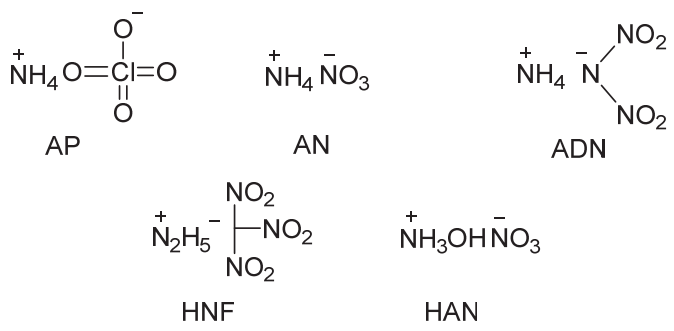

图 2 早期的含能离子盐

Figure 2 Energetic salts on early stage

2000 年左右 ${ }^{[12-13]}$, 为了协调含能化合物的能量与 感度之间的矛盾, 发展能量高、感度低、热稳定性好等 综合性能更优的新型含能化合物, 含能离子盐这一概念 被提出, 并被广泛应用于新型含能化合物的研制中, 含 能离子盐的合成、性能研究等逐步发展成为国内外含能 材料领域的研究热点之一 ${ }^{[14-17]}$. 相对于分子型含能化合 物, 含能离子盐普遍具有感度较低及热稳定性好等优 势, 且可通过阴阳离子的单独设计对其性能进行调节, 以满足炸药、推进剂等不同的技术需求 ${ }^{[18]}$. 目前已报道 的综合性能优良的新型含能离子盐包括联[3-(5-硝胺1,2,4-三唑)] 二氨基脲盐 ${ }^{[19]}$ (a)、1,1'-二羟基-5,5'-联四唑二 羟胺盐(TKX-50, b $)^{[4]} 、 1,1^{\prime}$-二羟基- 3,3'-二硝基-5,5'-联 $\left(1,2,4-\right.$ 三唑)二羟胺盐(c)(图 3) ${ }^{[20]}$ 等.

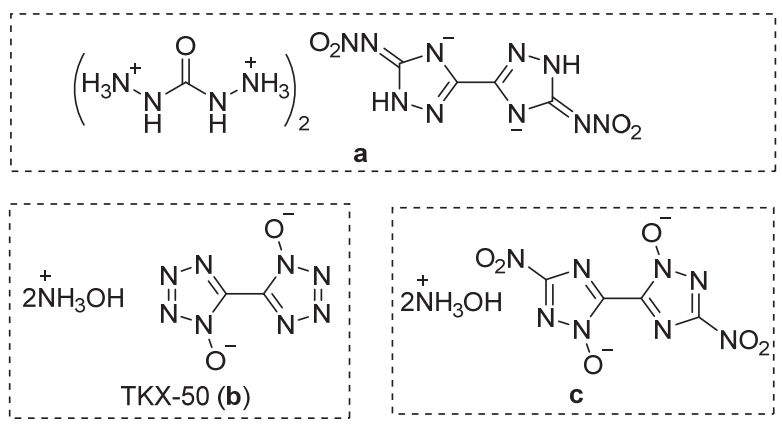

图 3 综合性优良的新型高能离子盐

Figure 3 Novel highly energetic salts with good comprehensive properties

高氮杂环被广泛应用于新型含能化合物的设计 中[21-23], 基于高氮杂环的含能化合物中含有大量 $\mathrm{N}-\mathrm{N}$ 单键、 $\mathrm{N}=\mathrm{N}$ 双键、 $\mathrm{C}-\mathrm{N}$ 单键及 $\mathrm{C}=\mathrm{N}$ 双键等高能键 ${ }^{[24]}$, 具有密度高、生成焓高、分解产物绿色、较容易达到零 氧平衡等优点. 吡唑环是高氮杂环中的一种, 其两个氮 原子直接相连，同时环上还有三个直接相连的碳原子, 其中的 $\mathrm{NH}$ 和三个碳位点均可进行结构修饰. 吡唑 ${ }^{[25]}$ 是

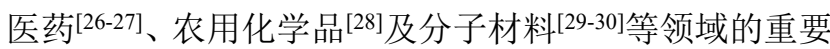
合成砌块, 其在含能化合物 ${ }^{[31-34]}$ 的设计中也获得了大量 应用. 相对于三唑和四唑杂环，吡唑环上带有更多的碳 原子，因此，其可修饰位点更多.

以吡唑环作为核心骨架, 在吡唑环上引入硝基、硝 胺基和羟基等官能团，来提高吡唑化合物的能量. 同时 利用硝胺、羟基等的酸性，与富氮碱进行酸碱中和来制 备具有高氧平衡、高能、低感的吡唑含能离子盐. 具体 的结构修饰途径主要有如下几种: (1)在吡唑环的碳原子 上引入富氧的硝基 ${ }^{[35]}$, 提高其氧平衡、密度及爆轰性能; (2)在吡唑环的碳或氮上引入氨基，可与硝基等形成分 子内和分子间的氢键 ${ }^{[36]}$, 降低感度. 研究发现, $\mathrm{N}-\mathrm{NH}_{2}$ 的引入可以提高含能化合物的生成焓，降低其感度； $C-\mathrm{NH}_{2}$ 的引入可以提高其密度、爆速、爆压等 ${ }^{[37]}$; (3)在 吡唑环上引入 $N$-羟基，可以增加化合物的密度、提高氧 
平衡和爆轰性能 ${ }^{[38]}$. 根据吡唑含能离子盐中吡唑环的 个数及连接方式不同, 本文将对文献报道的吡唑类含能 离子盐按单环吡唑含能离子盐、联环吡唑含能离子盐和 稠环吡唑含能离子盐进行分类阐述.

\section{1 吡唑含能离子盐}

\section{1 单环吡唑含能离子盐}

\subsection{1 单环吡唑含能离子盐的合成}

3,4,5-三硝基吡唑(TNP)是唯一全碳硝化的单环吡 唑类化合物 ${ }^{[39]}$, 其密度高达 $1.867 \mathrm{~g} \cdot \mathrm{cm}^{-3}$, 热稳定性高 于 $200{ }^{\circ} \mathrm{C}$, 爆速为 $9000 \mathrm{~m} \cdot \mathrm{s}^{-1}$, 爆压为 $37.09 \mathrm{GPa}$, 但

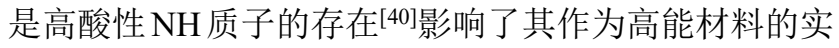
际应用. 因此, 制备其衍生物及离子盐意义重大. 2010 年, 张延强等 ${ }^{[41]}$ 以 3,5-二硝基- $1 H$-吡唑为原料, 经过三 甲基肼碘化物胺化(收率 $60 \%$ )、30\%双氧水氧化(收率 93\%)得到 3,4,5-三硝基吡唑(1). 化合物 1 与富氮碱进行 酸碱中和, 制备得到了含能离子盐 $\mathbf{2} \mathbf{a} \sim \mathbf{2 h}$, 反应收率为 $85 \% \sim 86 \%$, 合成路线如 Scheme 1 所示. 3,4,5-三硝基吡 唑银盐与相应的卤盐反应制备得到了化合物 $\mathbf{2 i} \sim \mathbf{2 m}$ (Scheme 1). 作者采用核磁共振谱、红外光谱、单晶 $\mathrm{X}$ 射线衍射等对所合成的含能离子盐进行了结构表征. 经 过测试, 它们的密度在 $1.61(\mathbf{2 j})$ 到 $1.77(\mathbf{2 d}) \mathrm{g} \cdot \mathrm{cm}^{-3}$ 之间. 热分解温度在 $167(\mathbf{2 b}, \mathbf{2 k})$ 到 $243{ }^{\circ} \mathrm{C}(\mathbf{2 f})$ 之间. 爆压在 23.7 (2j)到 31.9 (2d) GPa 之间, 爆速在 7586 (2j)到 8543 (2d) $m \cdot \mathrm{s}^{-1}$ 之间. 除化合物 $2 \mathbf{k}(35 \mathrm{~J})$ 和 $2 \mathbf{a}(40 \mathrm{~J})$ 外, 其它 盐的撞击感度都大于 $40 \mathrm{~J}$. 比较胍盐 $2 \mathrm{~g}$ 、氨基胍盐 $\mathbf{2 h}$ 、 二氨基胍盐 21 和三氨基胍盐 $\mathbf{2 m}$ 的物化参数及性能, 发 现随着氨基取代个数的增加, 含能离子盐的热分解温度 逐渐降低, 生成焓逐渐增加, 密度、爆压、爆速则呈现 先增大后减小, 然后再增大的现象. 这些离子盐中, 4氨基-1,2,4-三唑盐(2d)的密度为 $1.77 \mathrm{~g} \cdot \mathrm{cm}^{-3}$, 撞击感度 大于 $40 \mathrm{~J}$, 其爆轰性能 $\left(P=31.9 \mathrm{GPa}, D=8543 \mathrm{~m} \cdot \mathrm{s}^{-1}\right)$ 优 于 1,3,5-三氨基-2,4,6-三硝基苯(TATB, $P=31.2 \mathrm{GPa}$, $\left.D=8114 \mathrm{~m} \cdot \mathrm{s}^{-1}\right)$.

2012 年, 张延强等 ${ }^{[42]}$ 以 3,4,5-三硝基吡唑(1)为原料 制备了其铵盐 3 , 然后以水为溶剂, 使用过硫酸氢钾 (Oxone)在 $55{ }^{\circ} \mathrm{C}$ 对化合物 3 进行氧化制备得到 1-羟基$3,4,5$-三硝基吡唑，反应液经过乙醚萃取后用过量氨水 进行中和，浓缩后经过结晶以 $65 \%$ 的收率制备得到化合 物 4. 在水中用浓硫酸对化合物 4 进行酸化和萃取, 浓 缩后以 $95 \%$ 的收率得到油状物 $\mathbf{5}$. 最后, 化合物 $\mathbf{5}$ 与不 同的碱进行酸碱中和，以 $65 \% \sim 90 \%$ 的收率制备得到 1着基-3,4,5-三硝基吡唑含能离子盐 $\mathbf{6} \mathbf{a} \sim \mathbf{6} \mathbf{f}$ (Scheme 2). 与化合物 3 相比, $N$-氧化后密度由 $1.73 \mathrm{~g} \cdot \mathrm{cm}^{-3}$ (3)增加到 $1.82 \mathrm{~g} \cdot \mathrm{cm}^{-3}(4)$, 且氧平衡增加了一倍, 爆压爆速也有

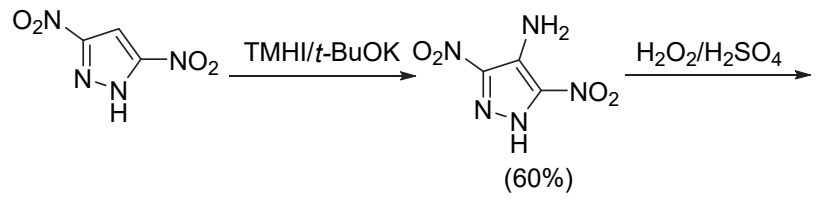<smiles>O=[N+]([O-])c1n[nH]c([N+](=O)[O-])c1[N+](=O)[O-]</smiles><smiles>Nc1n[nH]c(N)n1</smiles><smiles>N=C(N)Nc1nnc(NC(N)=[NH2+])nn1</smiles><smiles>N[NH+]=C(N)[18OH]</smiles>

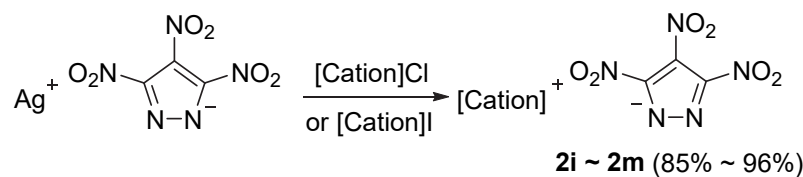

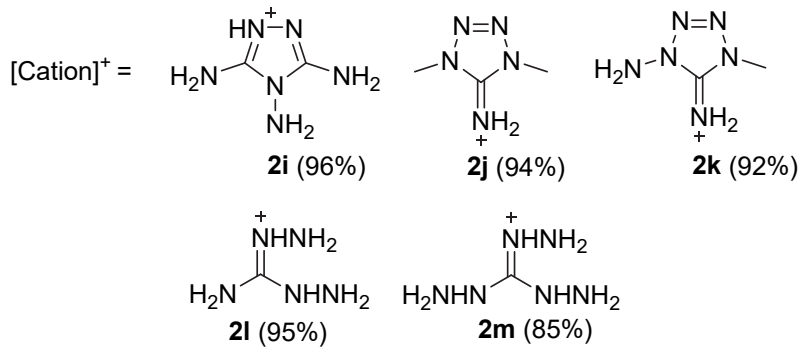

图式 $13,4,5$-三硝基吡唑含能离子盐的合成

Scheme 1 Synthesis of energetic salts based on 3,4,5-trinitropyrazole

相应提高. 这些盐的分解温度在 $118(6 \mathbf{6 d})$ 到 $186(6 \mathrm{6e}){ }^{\circ} \mathrm{C}$ 之间, 密度介于 $1.72(6 \mathrm{a})$ 到 $1.82(4) \mathrm{g} \bullet \mathrm{cm}^{-3}$ 之间. 爆压 在 28.8 (6a)到 35.1 (4) GPa 之间, 爆速在 8175 (6b)到 $8676(4) \mathrm{m} \cdot \mathrm{s}^{-1}$ 之间. 多数盐的撞击感度都大于 $40 \mathrm{~J}$. 其 中, 铵盐 4 综合性能最好, 密度为 $1.82 \mathrm{~g} \bullet \mathrm{cm}^{-3}$, 其爆轰 性能 $\left(P=35.1 \mathrm{GPa}, D=8676 \mathrm{~m} \cdot \mathrm{s}^{-1}\right)$ 非常接近 $\mathrm{RDX}(P=$ $\left.38.0 \mathrm{GPa}, D=8983 \mathrm{~m} \cdot \mathrm{s}^{-1}\right)$.

Schmidt 等 ${ }^{[43]}$ 于 2001 年合成了 4-氨基-3,5-二硝基吡 唑(LLM-116, 7). 该化合物的密度达到了 $1.90 \mathrm{~g} \bullet \mathrm{cm}^{-3}$, 爆速为 $8240 \mathrm{~m} \cdot \mathrm{s}^{-1}$, 爆压为 $29.4 \mathrm{GPa}$, 其具有能量密度 高、热稳定好、感度低的特点. 2012 年, 张延强等 ${ }^{[44]}$ 通过理论计算发现 LLM-116 的硝化产物 8 密度为 1.97 $\mathrm{g} \cdot \mathrm{cm}^{-3}$, 其爆轰性能优于 $3,4,5$-三硝基吡唑，但该化合 物在室温下不稳定. 于是他们使用浓硝酸/浓硫酸硝 


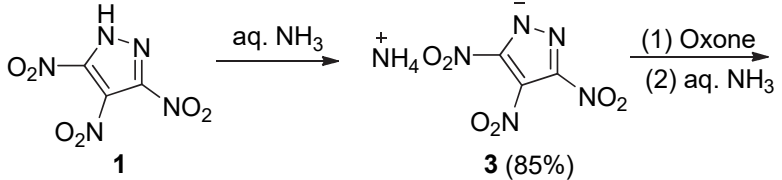

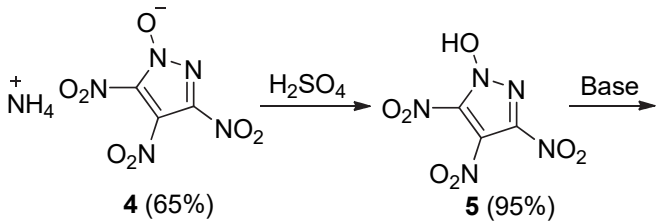

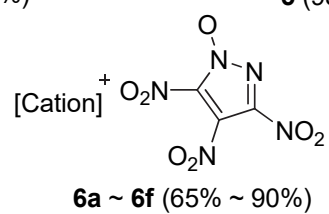

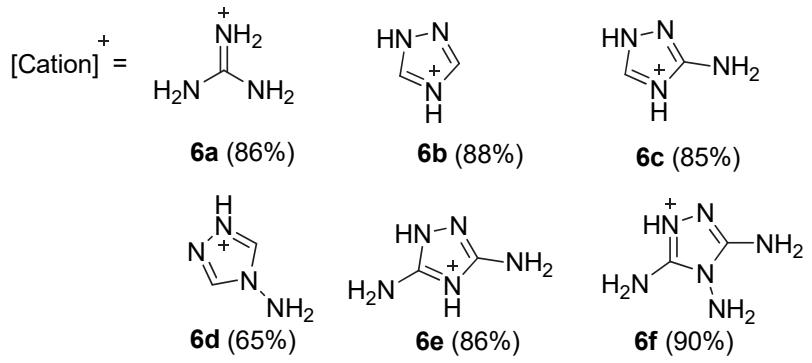

图式 2 1-羟基-3,4,5-三硝基吡唑含能离子盐的合成 Scheme 2 Synthesis of energetic salts based on 1-hydroxyl3,4,5-trinitropyrazole

化 4-氨基-3,5-二硝基吡唑(7), 硝化产物 8 与过量氨 水反应后经重结晶, 以 $81 \%$ 的收率制备得到化合物 9. 该化合物与硝酸银反应, 以 $97 \%$ 的收率得到银盐 10. 最后, 银盐 10 与不同富氮碱的盐酸盐发生复分 解反应，以 $80 \% \sim 94 \%$ 的收率制备得到含能离子盐 11a 11n (Scheme 3). 这些离子盐的密度介于 1.64 (11c, 11i)到 1.80 (11a) $\mathrm{g} \cdot \mathrm{cm}^{-3}$ 之间. 它们的爆压介于 23.27 (111)到 37.42 (11a) GPa 之间, 爆速介于 7713 (111)到 9013 (11a) $\mathrm{m}^{\circ} \mathrm{s}^{-1}$ 之间, 除化合物 11a $(30 \mathrm{~J}) 、 11 \mathrm{~b}(5 \mathrm{~J})$ 和 $11 \mathrm{~m}(5 \mathrm{~J})$ 外, 其它盐的撞击感度均大于 $40 \mathrm{~J}$. 它们的热 分解温度介于 115 (11c) 到 $229(\mathbf{1 1 h}){ }^{\circ} \mathrm{C}$ 之间, 比较三唑 盐 11c、3-氨基三唑盐 11d、3,5-二氨基三唑盐 $11 \mathrm{f}$ 和 3,4,5三氨基三唑盐 $11 \mathrm{~g}$ 的性能发现, 随着三唑上氨基数量的 增多, 热分解温度升高, 从 $115{ }^{\circ} \mathrm{C}$ (11c)升高到 $194{ }^{\circ} \mathrm{C}$ (11g), 爆压、爆速则呈现先增大再减小再增大的现象. 这一系列含能离子盐中, 3,4,5-三氨基三唑盐 $11 \mathrm{~g}$ 的爆轰 性能最优 $\left(P=27.9 \mathrm{GPa}, D=8342 \mathrm{~m} \cdot \mathrm{s}^{-1}\right)$.

含能化合物中引入 $N-\mathrm{NH}_{2}$ 不仅可以提高生成焓，同 时, 额外的氨基还可以增加化合物中的氢键数量, 起到 降低其感度的效果. 2015 年, 尹平等 ${ }^{[45]}$ 使用羟胺- $O$-磺 酸对 LLM-116 进行胺化, 以 $61 \%$ 的收率得到 1,4-二氨

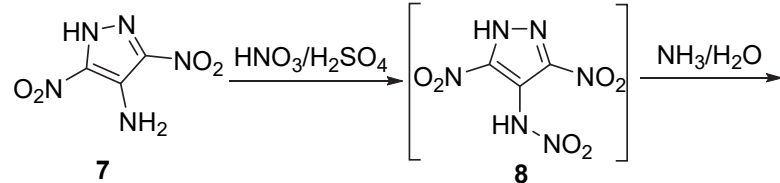<smiles>CC(C)O[N+](=O)[O-]</smiles>

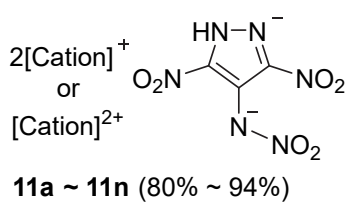

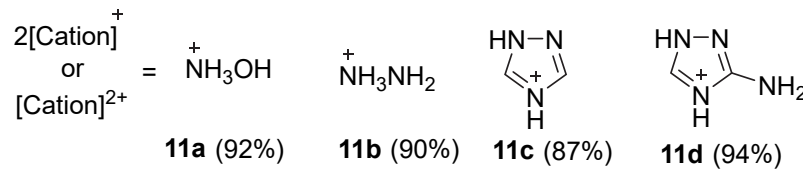<smiles></smiles><smiles>NNC(=[NH2+])NNC(=[18O])NN</smiles><smiles>[NH2+]=C([18OH])NC(=O)N[NH3+]</smiles>

图式 3 4-硝胺-3,5-二硝基吡唑含能离子盐的合成 Scheme 3 Synthesis of 4-nitramino-3,5-dinitropyrazole-based salts

基-3,5-二硝基吡唑(12). 然后，使用硝硫混酸对化合物 12 进行硝化, 硝化产物与过量氨水反应后经重结晶, 以 $64 \%$ 的收率制备得到化合物 13 , 该化合物与硝酸 银反应, 以 $93 \%$ 的收率得到银盐 14. 最后, 银盐 14 与不同富氮碱的盐酸盐发生复分解反应，以 $91 \%$ 94\%的收率制备得到含能离子盐 15a 15b (Scheme 4). 它们的热分解温度介于 139 (13)到 152 (15b) ${ }^{\circ} \mathrm{C}$ 之 间, 密度在 $1.75(\mathbf{1 5 b})$ 到 $1.85(\mathbf{1 5 a}) \mathrm{g} \bullet \mathrm{cm}^{-3}$ 之间. 爆压和 爆速分别介于 35.1 (13) 到 40.2 (15a) GPa 和 8982 (13)到 9410 (15a) $\mathrm{m} \cdot \mathrm{s}^{-1}$ 之间. 撞击感度介于 $5(\mathbf{1 5 b})$ 到 $12(\mathbf{1 3}) \mathrm{J}$ 之间, 摩擦感度介于 60 (15b)到 $120(13) \mathrm{N}$ 之间. 其中, 羟胺盐(15a)的爆轰性能最佳, 与 $\operatorname{HMX}(P=41.5 \mathrm{GPa}$, $D=9221 \mathrm{~m} \cdot \mathrm{s}^{-1}$ )相当. 
<smiles>CC(C)(C)[N+](=O)[O-]</smiles>

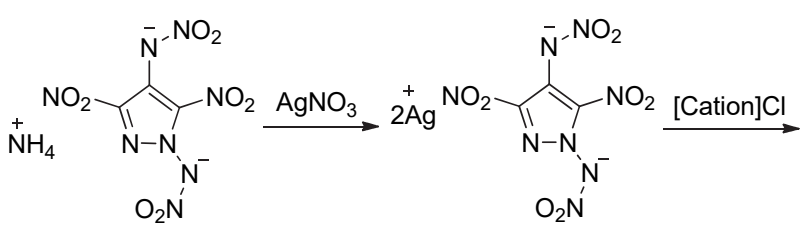<smiles>CC(C)(C)O[Na]</smiles>

[Cation] ${ }^{+}=\mathrm{NH}_{3} \mathrm{OH}^{+} \quad \mathrm{N}_{2} \mathrm{H}_{5}^{+}$

图式 4 1,4-二硝胺-3,5-二硝基吡唑含能离子盐的合成 Scheme 4 Synthesis of 1,4-nitramino-3,5-dinitropyrazole-based salts

同时，尹平等[45]还采用发烟硝酸对 LLM-116 的同 分异构体 5-氨基-3,4-二硝基吡唑(16)进行了硝化，以 94\%的收率制备得到硝胺化合物 17. 该化合物进一步与 不同的富氮碱发生酸碱中和反应，以 $93 \% \sim 97 \%$ 的收 率制备得到了 5-硝胺-3,4-二硝基吡唑系列含能离子盐 18a 18i (Scheme 5). 它们的热分解温度介于 130 (18i) 到 200 (18d) ${ }^{\circ} \mathrm{C}$ 之间, 密度介于 1.72 (18c) 到 1.88 (18i) g• $\mathrm{cm}^{-3}$ 之间. 爆压和爆速分别介于 28.3 (18c) 到 39.5 (19i) $\mathrm{GPa}$ 和 8319 (18c) 到 $9237(\mathbf{1 8 i}) \mathrm{m} \cdot \mathrm{s}^{-1}$ 之间. 它们的撞击 感度和摩擦感度分别介于 6 (18g)到 40 (18c) J 和 60 $(\mathbf{1 8 g})$ 到 $360(\mathbf{1 8 c}) \mathrm{N}$ 之间.

2017 年, 邓沐聪等 ${ }^{[46]}$ 以乙酰乙酸乙酯(19)为原料, 与水合肼一步关环以 93\%的收率制备得到 5-甲基- $1 H$ 吡唑-3-(2H)-酮(20), 其经过硝硫混酸硝化后得到化合物 21(收率 73\%). 最后, 化合物 21 再与不同的富氮碱发生 酸碱中和反应，以 $77 \% \sim 88 \%$ 的收率制备得到系列含 能离子盐 $22 \mathrm{a} \sim 22 \mathrm{c}$ (Scheme 6). 它们的密度介于 1.62 (22a) 到 $1.64(\mathbf{2 2 b}) \mathrm{g} \cdot \mathrm{cm}^{-3}$ 之间, 它们的热分解温度介于 181 (22b) 到 244 (22a) ${ }^{\circ} \mathrm{C}$ 之间. 利用 Explo5 软件计算出 它们的爆轰性能, 爆速和爆压介于 7776 (22a)到 8339 (22c) $\mathrm{m} \cdot \mathrm{s}^{-1}$ 和 20.3 (22a) 到 23.8 (22c) GPa 之间. 撞击感 度在 23 (22c) 到 28 (22a) $\mathrm{J}$ 之间, 摩擦感度均为 $240 \mathrm{~N}$.

在唑类含能化合物中引入 $\mathrm{N}-\mathrm{O}$ 键, 可以提高化合 物的氧平衡和密度, 从而使得化合物的爆轰性能得到提 升. 2017 年, 尹平等 ${ }^{[47]}$ 首先尝试用 Oxone 氧化 LLM-116 制备化合物 $\mathbf{5}$, 但得到的产物却是化合物 $\mathbf{1}$ 和 $\mathbf{5}$ 的混合

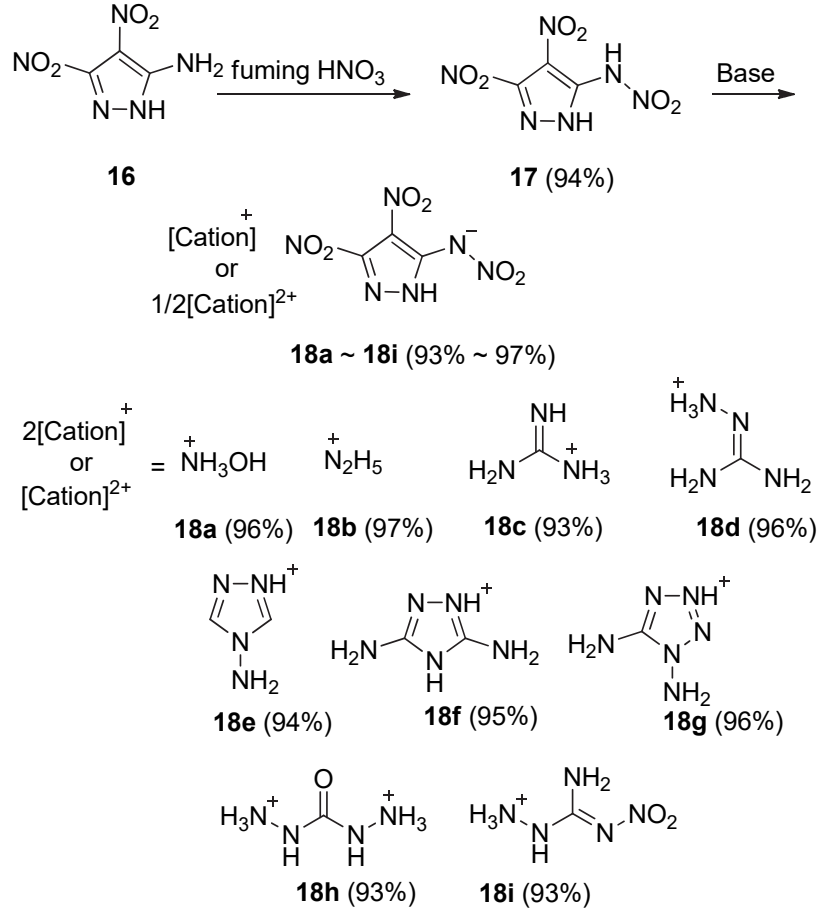

图式 5 5-硝胺-3,4-二硝基吡唑含能离子盐的合成 Scheme 5 Synthesis of 5-nitramino-3,4-dinitropyrazole-based salts
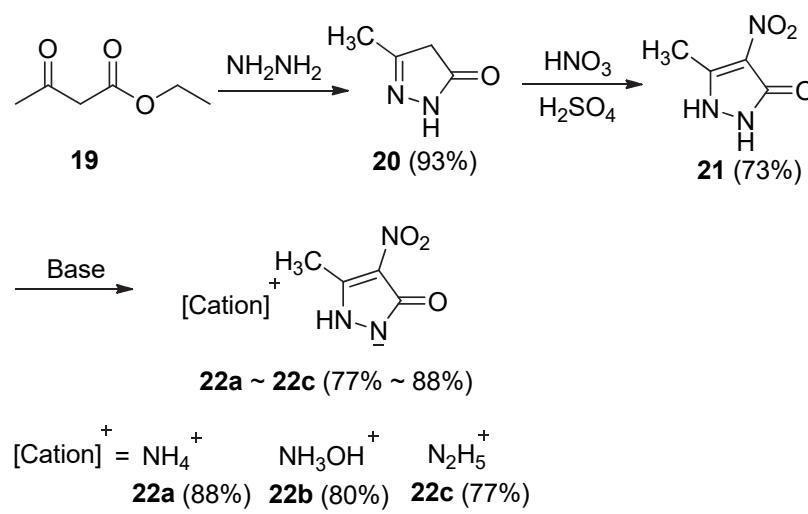

图式 6 5-甲基-4-硝基-1H-吡唑-3-(2H)-酮的含能离子盐的合 成

Scheme 6 Synthesis of energetic salts based on 5-methyl4-nitro-1 $H$-pyrazol-3-(2H)-one

物. 于是改为先使用质量浓度 $30 \% \mathrm{H}_{2} \mathrm{O}_{2}$ /浓硫酸氧化 LLM-116, 以 $69 \%$ 的收率得到了 3,4,5-三硝基吡唑(1), 然后再用 Oxone 氧化化合物 1 得到化合物 $\mathbf{5}$. 化合物 $\mathbf{5}$ 与氨的甲醇溶液反应制备得到了相应的铵盐 $23 \mathrm{a}$, 两步 收率是 $64 \%$. 铵盐 23a 再与胍类盐酸盐在水中发生复分 解反应，以 $72 \% \sim 83 \%$ 的收率制备得到了含能离子盐 23b 23d (Scheme 7). 它们的热分解温度介于 169 (23c) 到 214 (23d) ${ }^{\circ} \mathrm{C}$ 之间, 密度介于 1.71 (23b)到 1.75 (23d) $\mathrm{g} \cdot \mathrm{cm}^{-3}$ 之间. 爆压和爆速分别介于 26.4 (23b) 到 30.7 (23d) $\mathrm{GPa}$ 和 $8200(\mathbf{2 3 b})$ 到 8877 (23d) $\mathrm{m} \bullet \mathrm{s}^{-1}$ 之间. 撞击 
感度均为 $40 \mathrm{~J}$, 摩擦感度均为 $360 \mathrm{~N}$. 其中三氨基胍盐 (23d) 除密度外, 其它性能与 $\operatorname{RDX}(P=38.0 \mathrm{GPa}, D=$ $\left.8983 \mathrm{~m} \cdot \mathrm{s}^{-1}\right)$ 相当.

$$
\text { [Cation }]^{+}=
$$

图式 7 1-差基-4-氨基-3,5-1H-二硝基吡唑含能离子盐的合成 Scheme 7 Synthesis of energetic salts based on 1-hydroxyl-4amino-3,5-dinitro- $1 H$-pyrazole

2018 年, Bölter 等 ${ }^{[48]}$ 用 Oxone 分别氧化 3,4-二硝基 吡唑和 3,5-二硝基吡唑, 得到其对应的 $N$-差基吡唑 25a 和 25b, 收率分别为 $68 \%$ 和 $61 \%$. 它们再进一步与不同 的碱反应, 得到含能离子盐 $26 \mathrm{a} \sim 26 \mathrm{c}$ 和 $27 \mathrm{a} \sim 27 \mathrm{c}$ (Scheme 8). 它们的密度在 1.62 (27a)到 1.70 (26b) g• $\mathrm{cm}^{-3}$ 之间. 热分解温度介于 167 (26a) 到 $266(27 b){ }^{\circ} \mathrm{C}$ 之 间. 爆压和爆速分别介于 24.2 (27b)到 28.2 (26a) GPa 和 7909 (27a)到 8279 (26a) $\mathrm{m} \cdot \mathrm{s}^{-1}$ 之间. 这些含能离子盐中, 1-差基-3,4-二硝基吡唑铵盐(26a)的爆速最高, 为 8279 $\mathrm{m} \cdot \mathrm{s}^{-1}$, 低于 $\operatorname{RDX}\left(D=8983 \mathrm{~m} \cdot \mathrm{s}^{-1}\right)$, 但它的感度 $(\mathrm{IS}=30$ $J, F S=360 \mathrm{~N})$ 远优于 RDX (IS=7.5 J, FS=120 N).

2019 年, 张义迎等 ${ }^{[49]}$ 尝试在吡唑环上引入三硝基 甲基基团来提高化合物的氧平衡和爆轰性能. 他们以 3吡唑甲醛肟(28)为原料, 与盐酸差胺发生肟化反应, 以 $38.3 \%$ 的收率得到化合物 29. 然后, 用 $\mathrm{N}_{2} \mathrm{O}_{4}$ 对其进行硝 化，以 $15.0 \%$ 的收率得到化合物 30 (Scheme 9). 同年, 他们 ${ }^{[50]}$ 将化合物 30 与水合肼反应, 发生分子内重排和 酸碱中和反应，以 $61.9 \%$ 的收率得到了含能离子盐 31 . 该化合物具有良好的密度 $\left(d=1.80 \mathrm{~g} \cdot \mathrm{cm}^{-3}\right)$, 热分解温 度为 $129{ }^{\circ} \mathrm{C}$, 其生成焓 $\left(\Delta_{\mathrm{f}} H=194.8 \mathrm{~kJ} \cdot \mathrm{mol}^{-1}\right)$ 优于 $\mathrm{RDX}$ $\left(\Delta_{\mathrm{f}} H=86.3 \mathrm{~kJ} \cdot \mathrm{mol}^{-1}\right)$ 和 $\mathrm{HMX}\left(\Delta_{\mathrm{f}} H=116.1 \mathrm{~kJ} \bullet \mathrm{mol}^{-1}\right)$. 爆 速达到 $8790 \mathrm{~m} \bullet \mathrm{s}^{-1}$, 爆压达到 $33.8 \mathrm{GPa}$. 具有与 RDX $\left(P=38.0 \mathrm{GPa}, D=8983 \mathrm{~m} \cdot \mathrm{s}^{-1}\right)$ 相当的爆轰性能. 与其母 体分子 $30(\mathrm{IS}=2.5 \mathrm{~J}, \mathrm{FS}=36 \mathrm{~N})$ 相比, 化合物 $\mathbf{3 1}(\mathrm{IS}=7$ $\mathrm{J}, \mathrm{FS}=192 \mathrm{~N}$ )具有更优的撞击感度和摩擦感度.

2020 年，雷才金等 ${ }^{[51]}$ 以 3-硝基-4-氯肟吡唑(32)为原 料, 使用三氟乙酸酐/硝酸对其硝化, 得到油状物 33, 其

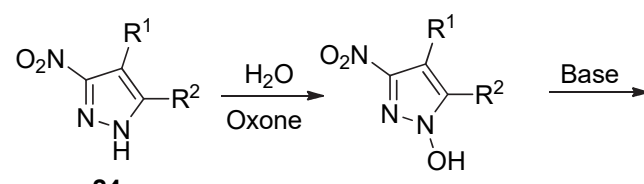

24

25a: $\mathrm{R}^{1}=\mathrm{NO}_{2} ; \mathrm{R}^{2}=\mathrm{H}(68 \%)$

25b: $R^{1}=\mathrm{H} ; \mathrm{R}^{2}=\mathrm{NO}_{2}(61 \%)$<smiles>[R]c1c([N+](=O)[O-])nn([O-])c1[R]</smiles>

26a $\sim 26 \mathrm{c}(58 \% \sim 74 \%)$

$27 a \sim 27 c(64 \% \sim 94 \%)$

$$
\begin{aligned}
& \text { [Cation }{ }^{+}=\quad \mathrm{NH}_{4}^{+} \\
& \mathrm{H}_{2} \mathrm{~N}^{\stackrel{+}{N}} \mathrm{NH}_{2} \\
& \text { 26a (74\%) } \\
& \text { 27a }(94 \%)
\end{aligned}
$$

图式 8 1-羟基-3,4-1H-二硝基吡唑和 1-羟基-3,5-二硝基 $1 H$ 吡唑含能离子盐的合成

Scheme 8 Synthesis of energetic salts based on 1-hydroxyl-3,4dinitro- $1 H$-pyrazole and 1-hydroxyl-3,5-dinitro- $1 H$--pyrazole

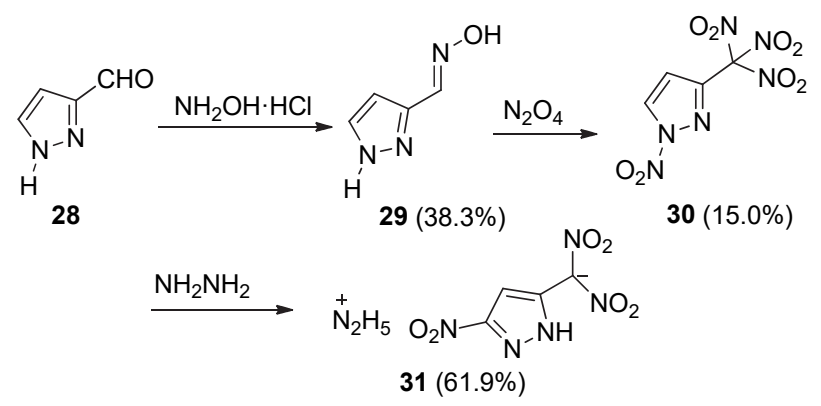

图式 95 -硝基-3-二硝基甲基- $2 H$-吡唑含能离子盐的合成 Scheme 9 Synthesis of energetic salts based on hydrazinium 5-nitro-3-dinitromethyl-2 $H$-pyrazole

与碘化钾的甲醇溶液反应，以 $31.7 \%$ 的收率制备了钾盐 34. 将其酸化、萃取后以 $40 \%$ 的收率得到化合物 35 . 最 后，化合物 35 与不同的富氮碱发生酸碱反应以 $60 \%$ $80 \%$ 的收率得到了含能离子盐 $\mathbf{3 6 a} \sim \mathbf{3 6 d}$ (Scheme 10). 它们的密度介于 $1.71(\mathbf{3 6 d})$ 到 $1.78(\mathbf{3 6 a}) \mathrm{g} \cdot \mathrm{cm}^{-3}$ 之间. 热 分解温度介于 $140(36 \mathrm{~d})$ 到 $166(36 \mathrm{~b}){ }^{\circ} \mathrm{C}$ 之间. 它们的爆 压和爆速分别介于 28.7 (36c) 到 34.1 (36b) GPa 和 8256 (36c) 到 $8700(\mathbf{3 6 b}) \mathrm{m} \cdot \mathrm{s}^{-1}$ 之间. 撞击感度均大于 $20 \mathrm{~J}$, 摩 擦感度在 162 (36d) 到 252 (36b) $\mathrm{N}$ 之间. 在这些含能盐 中, 三氨基胍盐 23d 除密度外, 其它性能与 $\mathrm{RDX}(P=$ $\left.38.0 \mathrm{GPa}, D=8983 \mathrm{~m} \cdot \mathrm{s}^{-1}\right)$ 相当. 羟铵盐 $36 \mathrm{~b}$ 表现出良好 的爆轰性能 $\left(P=34.1 \mathrm{GPa}, D=8700 \mathrm{~m} \cdot \mathrm{s}^{-1}\right)$, 与 $\operatorname{RDX}$ 相 当. 相比于其中性分子 35 , 铵盐 $36 \mathrm{a}$ 具有更高的密度、 更优异的爆轰性能、更高的分解温度和较低的机械感度.

上述单环吡坐含能离子盐及 TNT、RDX、HMX、 CL-20 的理化参数和爆轰性能见表 1 . 


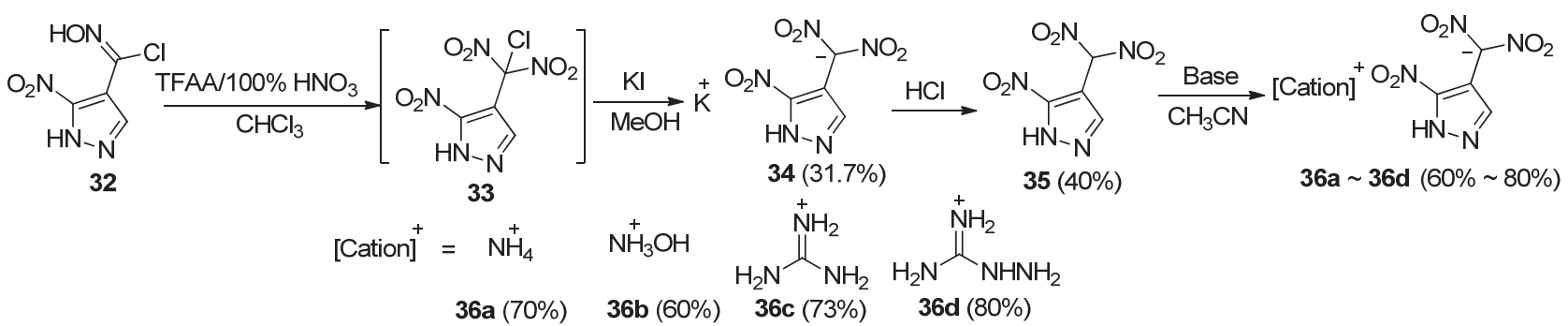

图式 10 3-硝基-4-二硝基甲基- $2 H$-吡唑含能离子盐的合成

Scheme 10 Synthesis of energetic salts based on 3-nitro-4-dinitromethyl-2H-pyrazole

表 1 单环吡唑离子盐的理化参数和爆轰性能

Table 1 Physicochemical properties and energetic properties of energetic salts based on monocyclic pyrazole

\begin{tabular}{|c|c|c|c|c|c|c|c|c|}
\hline Compd. & $T_{\mathrm{m}}{ }^{a} /{ }^{\circ} \mathrm{C}$ & $T_{\mathrm{d}}^{b} /{ }^{\circ} \mathrm{C}$ & $d^{c} /\left(\mathrm{g} \cdot \mathrm{cm}^{-3}\right)$ & $\Delta_{\mathrm{f}} H^{d} /\left(\mathrm{kJ} \bullet \mathrm{mol}^{-1}\right) /\left({\left.\mathrm{kJ} \bullet \mathrm{g}^{-1}\right)}^{-1}\right.$ & $P^{e} / \mathrm{GPa}$ & $D^{f} /\left(\mathrm{m} \cdot \mathrm{s}^{-1}\right)$ & IS $\mathrm{S}^{g} / \mathrm{J}$ & $\mathrm{FS}^{h} / \mathrm{N}$ \\
\hline $2 \mathbf{a}$ & - & 224 & 1.73 & $60.5 / 0.28$ & 29.9 & 8461 & 40 & - \\
\hline $2 \mathbf{b}$ & 158 & 167 & 1.69 & 299.0/1.10 & 25.6 & 7871 & $>40$ & - \\
\hline $2 \mathrm{c}$ & 171 & 171 & 1.71 & $273.5 / 0.95$ & 26.0 & 7972 & $>40$ & - \\
\hline 2d & 168 & 168 & 1.77 & $401.2 / 1.40$ & 31.9 & 8543 & $>40$ & - \\
\hline $2 \mathrm{e}$ & 188 & 196 & 1.76 & $235.6 / 0.78$ & 27.7 & 8216 & $>40$ & - \\
\hline $2 f$ & - & 243 & 1.68 & $452.3 / 0.75$ & 24.3 & 7817 & $>40$ & - \\
\hline $2 \mathrm{~g}$ & 163 & 235 & 1.66 & $28.3 / 0.11$ & 24.7 & 7865 & $>40$ & - \\
\hline $2 \mathrm{~h}$ & 136 & 222 & 1.69 & $133.6 / 0.48$ & 26.9 & 8134 & $>40$ & - \\
\hline $2 \mathrm{i}$ & 206 & 206 & 1.76 & $355.0 / 1.12$ & 28.8 & 8359 & $>40$ & - \\
\hline $2 \mathrm{j}$ & 166 & 219 & 1.61 & $375.0 / 1.19$ & 23.7 & 7586 & $>40$ & - \\
\hline $2 k$ & 120 & 167 & 1.64 & $459.8 / 1.45$ & 25.2 & 7922 & 35 & - \\
\hline 21 & 122 & 197 & 1.62 & $246.5 / 0.84$ & 25.3 & 7983 & $>40$ & - \\
\hline $2 m$ & 125 & 184 & 1.65 & $352.7 / 1.15$ & 27.2 & 8236 & $>40$ & - \\
\hline 4 & - & 176 & 1.82 & $35.1 / 0.15$ & 35.1 & 8676 & 6 & - \\
\hline $6 a$ & - & 171 & 1.72 & $3.1 / 0.01$ & 28.8 & 8176 & $>40$ & - \\
\hline $6 b$ & - & 140 & 1.73 & $274.9 / 0.95$ & 29.5 & 8175 & $>40$ & - \\
\hline $6 c$ & - & 132 & 1.73 & $250.5 / 0.83$ & 29.2 & 8177 & $>40$ & - \\
\hline 6d & - & 118 & 1.74 & $381.6 / 1.26$ & 30.8 & 8345 & $>40$ & - \\
\hline $6 e$ & - & 186 & 1.76 & $213.7 / 0.67$ & 29.7 & 8261 & $>40$ & - \\
\hline $6 f$ & - & 185 & 1.77 & $331.9 / 1.00$ & 31.1 & 8442 & $>40$ & - \\
\hline $11 \mathrm{a}$ & - & 147 & 1.80 & $54.2 / 0.19$ & 37.4 & 9013 & 30 & - \\
\hline $11 b$ & - & 171 & 1.75 & $274.7 / 0.97$ & 33.8 & 8917 & 5 & - \\
\hline $11 \mathrm{c}$ & - & 115 & 1.64 & $544.6 / 1.53$ & 25.3 & 7921 & $>40$ & - \\
\hline 11d & - & 167 & 1.75 & $496.6 / 1.29$ & 27.9 & 8244 & $>40$ & - \\
\hline $11 \mathrm{e}$ & 103 & 118 & 1.74 & $762.9 / 1.98$ & 29.7 & 8452 & $>40$ & - \\
\hline $11 f$ & - & 170 & 1.71 & $452.4 / 1.09$ & 27.1 & 8196 & $>40$ & - \\
\hline $11 \mathrm{~g}$ & - & 194 & 1.71 & 718.2/1.61 & 27.9 & 8342 & $>40$ & - \\
\hline $11 \mathrm{~h}$ & - & 229 & 1.66 & $-0.8 /-0.01$ & 24.3 & 7920 & $>40$ & - \\
\hline $11 \mathbf{i}$ & - & 180 & 1.64 & $227.9 / 0.62$ & 25.5 & 8117 & $>40$ & - \\
\hline $11 \mathrm{j}$ & - & 178 & 1.65 & $464.1 / 1.17$ & 27.5 & 8385 & $>40$ & - \\
\hline $11 \mathrm{k}$ & - & 172 & 1.65 & 701.5/1.65 & 28.9 & 8581 & 23 & - \\
\hline 111 & 132 & 189 & 1.69 & $-362.8 /-0.86$ & 23.3 & 7713 & $>40$ & - \\
\hline $11 \mathrm{~m}$ & - & 144 & 1.81 & $-108.6 /-0.35$ & 30.4 & 8378 & 5 & - \\
\hline $11 n$ & - & 166 & 1.72 & $-229.4 /-0.72$ & 24.4 & 7799 & $>40$ & - \\
\hline $15 a$ & - & 141 & 1.85 & 264.2/0.77 & 40.2 & 9410 & 8 & 80 \\
\hline $15 b$ & - & 152 & 1.75 & $489.3 / 1.42$ & 35.7 & 9066 & 5 & 60 \\
\hline $18 \mathrm{a}$ & - & 166 & 1.86 & $193.7 / 0.77$ & 38.5 & 9195 & 10 & 80 \\
\hline $18 \mathrm{~b}$ & - & 180 & 1.86 & $293.7 / 1.17$ & 38.7 & 9176 & 10 & 120 \\
\hline $18 \mathrm{c}$ & - & 171 & 1.72 & $122.3 / 0.44$ & 28.3 & 8319 & 40 & 360 \\
\hline
\end{tabular}




\begin{tabular}{|c|c|c|c|c|c|c|c|c|}
\hline Compd. & $T_{\mathrm{m}}{ }^{a} /{ }^{\circ} \mathrm{C}$ & $T_{\mathrm{d}}^{b} /{ }^{\circ} \mathrm{C}$ & $d^{c} /\left(\mathrm{g} \cdot \mathrm{cm}^{-3}\right)$ & 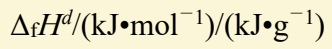 & $P^{e} / \mathrm{GPa}$ & $D^{f} /\left(\mathrm{m} \cdot \mathrm{s}^{-1}\right)$ & $\mathrm{IS}^{g} / \mathrm{J}$ & $\mathrm{FS}^{h} / \mathrm{N}$ \\
\hline 18d & - & 200 & 1.79 & $232.3 / 0.80$ & 32.2 & 8745 & 24 & 160 \\
\hline $18 \mathrm{e}$ & - & 177 & 1.78 & $488.9 / 1.62$ & 31.9 & 8645 & 20 & 160 \\
\hline $18 f$ & - & 183 & 1.81 & $320.4 / 1.01$ & 31.5 & 8629 & 30 & 240 \\
\hline $18 \mathrm{~g}$ & - & 153 & 1.84 & $720.5 / 2.27$ & 37.4 & 9170 & 6 & 60 \\
\hline $18 \mathrm{~h}$ & - & 142 & 1.77 & $416.7 / 0.79$ & 32.8 & 8652 & 20 & 120 \\
\hline $18 \mathrm{i}$ & - & 130 & 1.88 & $450.0 / 1.34$ & 39.5 & 9237 & 8 & 80 \\
\hline $22 a$ & - & 244 & 1.62 & $-147.3 /-0.92$ & 20.3 & 7776 & 28 & 240 \\
\hline 22b & - & 181 & 1.64 & $-93.3 /-0.53$ & 22.8 & 7929 & 26 & 240 \\
\hline $22 \mathrm{c}$ & - & 223 & 1.63 & $8.8 / 0.05$ & 23.8 & 8339 & 23 & 240 \\
\hline $23 b$ & - & 204 & 1.71 & $12.4 / 0.05$ & 26.4 & 8200 & 40 & 360 \\
\hline $23 c$ & - & 169 & 1.71 & $219.8 / 0.79$ & 28.0 & 8540 & 40 & 360 \\
\hline 23d & - & 214 & 1.75 & $337.2 / 1.15$ & 30.7 & 8877 & 40 & 360 \\
\hline $26 a$ & - & 167 & 1.68 & $68.7 / 0.36$ & 28.2 & 8279 & 10 & 360 \\
\hline $26 b$ & - & 180 & 1.70 & $27.0 / 0.12$ & 25.1 & 8063 & 30 & 360 \\
\hline $26 \mathrm{c}$ & 132 & 169 & 1.64 & $144.9 / 0.58$ & 24.7 & 8021 & 10 & 360 \\
\hline $27 a$ & - & 224 & 1.62 & $-253.4 /-1.21$ & 24.4 & 7909 & 30 & 288 \\
\hline $27 b$ & - & 266 & 1.68 & $7.8 / 0.03$ & 24.2 & 7935 & 40 & 360 \\
\hline $27 \mathrm{c}$ & - & 131 & 1.68 & $115.2 / 0.46$ & 25.7 & 8159 & 10 & 360 \\
\hline 31 & - & 129 & 1.80 & $194.8 / 0.78$ & 33.8 & 8790 & 7 & 192 \\
\hline $36 a$ & - & 141 & 1.78 & $85.4 / 0.36$ & 33.0 & 8601 & $>20$ & 192 \\
\hline $36 b$ & - & 166 & 1.80 & $135.5 / 0.54$ & 34.1 & 8700 & $>20$ & 162 \\
\hline $36 c$ & - & 161 & 1.72 & $43.8 / 0.16$ & 28.7 & 8256 & $>20$ & 240 \\
\hline 36d & - & 140 & 1.71 & $231.4 / 0.78$ & 30.1 & 8480 & $>20$ & 252 \\
\hline $\mathrm{TNT}^{i}$ & 81 & 290 & 1.65 & $-55.5 /-0.24$ & 23.5 & 7459 & 15 & 353 \\
\hline $\mathrm{RDX}^{i}$ & 205 & 210 & 1.81 & $86.3 / 0.39$ & 38.0 & 8983 & 7.5 & 120 \\
\hline $\mathrm{HMX}^{i}$ & 275 & 279 & 1.90 & $116.1 / 0.39$ & 41.5 & 9221 & 7 & 112 \\
\hline CL-20 ${ }^{i}$ & - & 215 & 2.03 & $365.4 / 0.83$ & 46.7 & 9455 & 4 & 48 \\
\hline
\end{tabular}

${ }^{a}$ Melting point. ${ }^{b}$ Decomposition temperature. ${ }^{c}$ Density. ${ }^{d}$ Calculated molar enthalpy of formation. ${ }^{e}$ Detonation pressure. ${ }^{f}$ Detonation velocity. ${ }^{g}$ Impact sensitivity. ${ }^{h}$ Friction sensitivity. ${ }^{i}$ Ref. [4].

\subsection{2 单环吡唑含能离子盐常用前体的合成}

3,4,5-三硝基吡唑(TNP)是单环吡唑含能离子盐合 成的常用前体, 我们对它的制备方法进行了归纳总结 (Scheme 11). Herve 等 ${ }^{[52]}$ 使用不同的方法制备得到 TNP, 他们采用硝酸 $/ 20 \%$ 发烟硫酸为硝化试剂硝化 3,5-二硝 基吡唑，以 $94 \%$ 的收率得到 TNP. 他们又使用过二硫酸 $\left(\mathrm{H}_{2} \mathrm{~S}_{2} \mathrm{O}_{8}\right)$ 分别氧化 LLM-116 和 5-氨基-3,4-二硝基吡唑, 分别以 $93 \%$ 和 37\%的收率得到 TNP (表 2, Entries 2, 5). 他们还以 5-氨基-3,4-二硝基吡唑为原料, 通过 Sandmyer 反应以 $80 \%$ 的收率得到 TNP (表 2, Entry 4). Dalinger 等 ${ }^{[53]}$ 采用硝酸/硫酸作为硝化试剂硝化 3,5-二硝

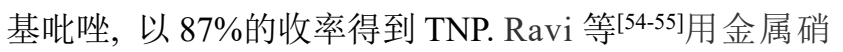
酸盐为硝化试剂对 3,5-二硝基吡唑进行硝化, TNP 的 制备收率在 $90 \%$ 以上. 赵秀秀等 ${ }^{[56]}$ 采用过硫酸氢钾 (Oxone)氧化 LLM-116, 以 $85 \%$ 的收率得到 TNP. Ravi 等 ${ }^{[57]}$ 硝化 3,4,5-三碘吡唑, 以 $92 \%$ 的收率得到 TNP.

上述合成中的重要化合物 LLM-116 的制备是以 $1 H$-吡唑为原料, 使用发烟硝酸对其进行硝化以 $88 \%$ 的 收率制备得到 $N$-硝基吡唑, 其在苯甲腈中 $180{ }^{\circ} \mathrm{C}$ 下进

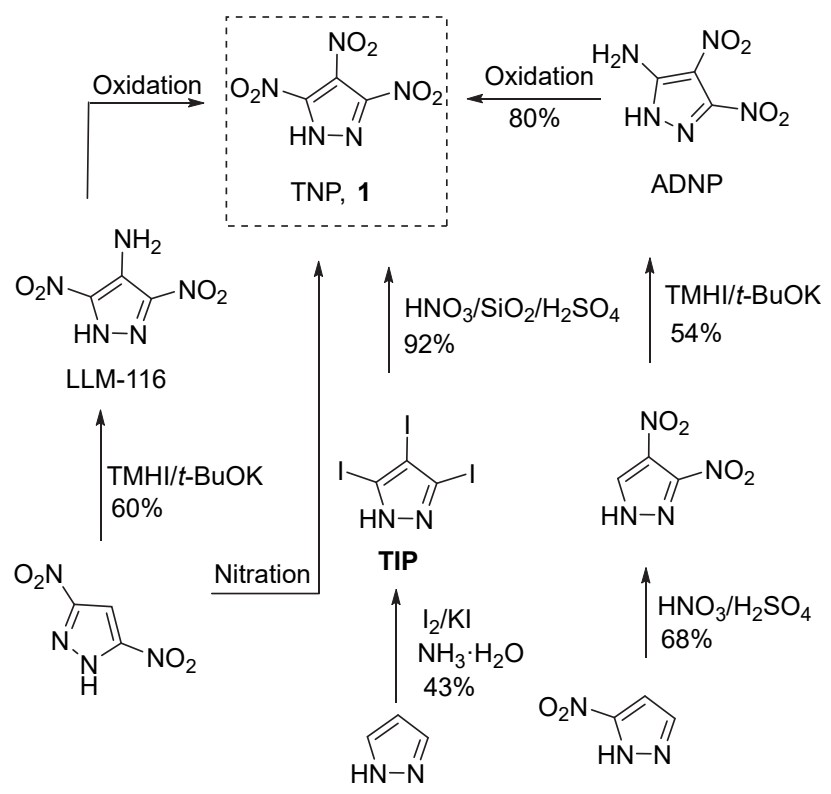

图式 $113,4,5$-三硝基吡唑(TNP)的合成

Scheme 11 Synthesis of 3,4,5-trinitropyrazole (TNP)

行热重排以 $79 \%$ 的收率得到 3-硝基- $1 H$-吡唑. 使用硝 
表 2 合成 TNP 的不同方法

Table 2 Different ways to synthesize TNP

\begin{tabular}{cllc}
\hline Entry & Starting material & Reagent & Yield/\% \\
\hline 1 & LLM-116 & $\mathrm{H}_{2} \mathrm{O}_{2} / \mathrm{H}_{2} \mathrm{SO}_{4}$ & 93 \\
2 & LLM-116 & $\mathrm{H}_{2} \mathrm{~S}_{2} \mathrm{O}_{8}$ & 93 \\
3 & LLM-116 & Oxone & 85 \\
4 & ADNP & $\mathrm{NaNO}_{2} / \mathrm{H}_{2} \mathrm{SO}_{4}$ & 80 \\
5 & ADNP & $\mathrm{H}_{2} \mathrm{~S}_{2} \mathrm{O}_{8}$ & 37 \\
6 & TIP & $\mathrm{HNO}_{3} / \mathrm{SiO}_{2} / \mathrm{H}_{2} \mathrm{SO}_{4}$ & 92 \\
\hline
\end{tabular}

酸/乙酸/乙酸酐对 3-硝基- $1 H$-吡唑进行硝化, 以 $85 \%$ 的 收率得到 1,3-二硝基- $1 H$-吡唑. 其再在苯甲腈中进行热 重排以 78\%的收率得到 3,5-二硝基吡唑. 最后, 使用三 甲基肼碘化物对 3,5-二硝基吡唑进行胺化, 以 $60 \%$ 收率 的收率制备得到 LLM-116 (Scheme 12) ${ }^{[58]}$.

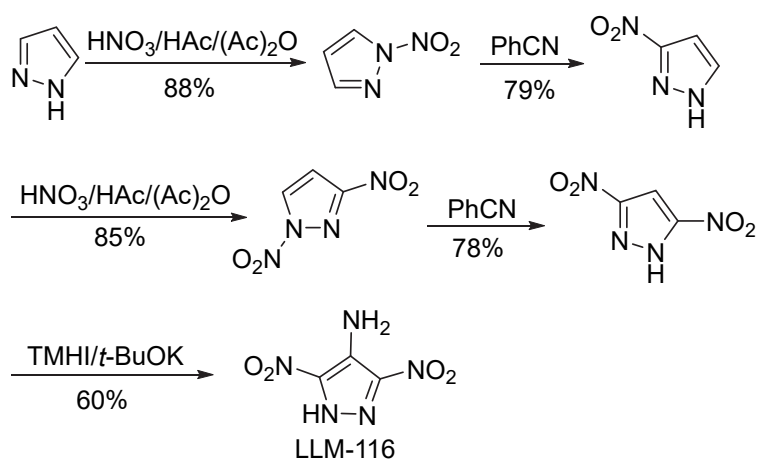

图式 12 LLM-116 的合成

Scheme 12 Synthesis of LLM-116

1.1 .3 单环吡唑含能离子盐合成中常用反应的反应 机理

3,4,5-三硝基吡唑(TNP)的合成涉及到的反应有重 排反应和异常亲核取代氢(VNS)反应. 1971 年, Janssen 等[59]发现 $N$-硝基吡唑经硝基的[1,5]- $\sigma$ 重排反应可得到 3-硝基吡唑(Scheme 13). 1973 年, Janssen 等 ${ }^{[60]}$ 详细研究 了 $N$-硝基吡唑的重排反应, 发现其不受酸或碱的影响, 动力学分析结果表明此重排反应为一级动力学反应. 加热重排过程中, $\mathrm{N}$ 原子上的硝基发生异构化. 在适 宜的溶剂和温度下, $N-\mathrm{NO}_{2}$ 重排形成更稳定的 $C-\mathrm{NO}_{2}$.

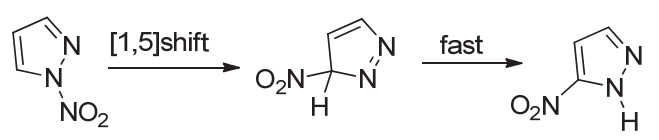

图式 $13 N$-硝基吡唑的重排

Scheme 13 Rearrangement of the $N$-nitropyrazole

杂环胺化试剂有三甲基肼碘化物( TMHI)、羟胺- $O-$ 磺酸(HOSA)、对甲苯磺酰羟胺(THA)、2,4,6-三甲苯磺 酰差胺(MSH)和 4-氨基-1,2,4-三氮唑(ATA)等. 异常亲核 取代(VNS)反应是硝基芳烃的邻对位质子被氨基等取
代的反应. 如 Scheme 14 所示, 将带有离去基团(X)的 碳负离子加成到亲电芳环上, 然后消除 $\mathrm{HX}$ 实现重芳构 化 ${ }^{[61]}$. 类似的氨基亲核体 $\left(\mathrm{X}-\mathrm{NH}_{2}\right)$ 也能发生 VNS 反应, $\mathrm{X}$ 作为稳定负电荷的辅助基团并以 $\mathrm{HX}$ 形式消除, 最终引 起 $\sigma$ 中间体加合物的重芳构化.

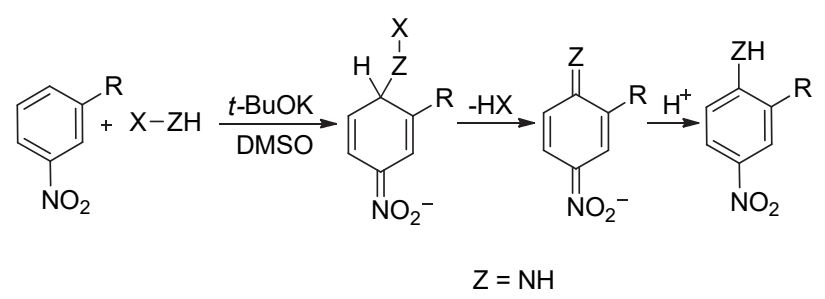

图式 14 VNS 胺化反应机理

Scheme 14 Mechanism of VNS amination

\section{2 联环吡唑含能离子盐}

联环吡唑含能离子盐从包含的结构单元看, 可以细 分为 $\mathrm{C}-\mathrm{N}$ 桥联、 $\mathrm{C}-\mathrm{C}$ 桥联、 $\mathrm{N}-\mathrm{N}$ 桥联及 $\mathrm{N}=\mathrm{N}$ 桥联的 联环吡唑含能离子盐. 从连接杂环的类型上可以分为吡 唑一吡唑联环、吡唑与其它杂环构成的联环. 其中已经合 成了多种性能优异的 $\mathrm{C}-\mathrm{N}$ 联环、 $\mathrm{C}-\mathrm{C}$ 联环、 $\mathrm{N}=\mathrm{N}$ 联环 吡唑含能离子盐. 下面按结构单元进行分类阐述.

\subsection{1 $\mathrm{C}-\mathrm{N}$ 桥联的联环吡唑含能离子盐}

相对于单环吡唑, 联环吡唑含有更多的 $\mathrm{N}-\mathrm{N}$ 键和 $\mathrm{C}-\mathrm{N}$ 键等高能键，且化合物的热稳定性更好. 2014 年， 李川等 ${ }^{[62]}$ 首先尝试了 LLM-116 分别与 4-氯-3,5-二硝基 吡唑及 3,4,5-三硝基吡唑(TNP)反应来制备化合物 40 , 但未到目标产物. 然后, 他们在碱性条件下将 TNP 与 4氯吡唑反应，以 $62 \%$ 的收率成功制备了中间体 37. 采用 硝硫混酸硝化 37 以 $65 \%$ 的收率制备得到化合物 38. 其 用氨水进行氨解，以 $70 \%$ 的收率得到铵盐 39,39 经过硫 酸酸化以 $85 \%$ 的收率得到化合物 $\mathbf{4 0}$. 化合物 40 与不同 的富氮碱发生酸碱中和反应以 $86 \% \sim 91 \%$ 的收率得到联 吡唑含能离子盐 $\mathbf{4 1 f} \sim \mathbf{4 1 h}$. 化合物 40 与氢氧化钡在水 中反应后向其中加入相应的硫酸盐, 一锅法制备得到离 子盐 41a 41e (80\% 93\%, Scheme 15). 热分解温度优 异, 在 228 (41a)到 297 (41f) ${ }^{\circ} \mathrm{C}$ 之间. 它们的密度介于 1.67 (41b)到 1.82 (41f) $\mathrm{g} \cdot \mathrm{cm}^{-3}$ 之间. 爆压和爆速分别介 于 27.1 (41b)到 37.1 (41e) GPa 和 8088 (41b)到 8449 (41f) $\mathrm{m} \cdot \mathrm{s}^{-1}$ 之间. 它们的撞击感度都大于 $40 \mathrm{~J}$, 属于不敏感含 能材料. 铵盐 39 分解温度达到 $262{ }^{\circ} \mathrm{C}$, 密度为 1.88 $\mathrm{g} \cdot \mathrm{cm}^{-3}$, 生成焓为 $274.7 \mathrm{~kJ} \cdot \mathrm{mol}^{-1}$. 爆轰性能也很出色, 爆压为 $34.6 \mathrm{GPa}$, 爆速为 $8615 \mathrm{~m} \cdot \mathrm{s}^{-1}$, 能量与 $\mathrm{RDX}(P=$ $38.0 \mathrm{GPa}, D=8983 \mathrm{~m} \cdot \mathrm{s}^{-1}$ )相当, 但感度(IS>40 J)却远低 于 $\operatorname{RDX}(I S=7.5 \mathrm{~J})$, 是具有应用前景的 $\operatorname{RDX}$ 替代物. 


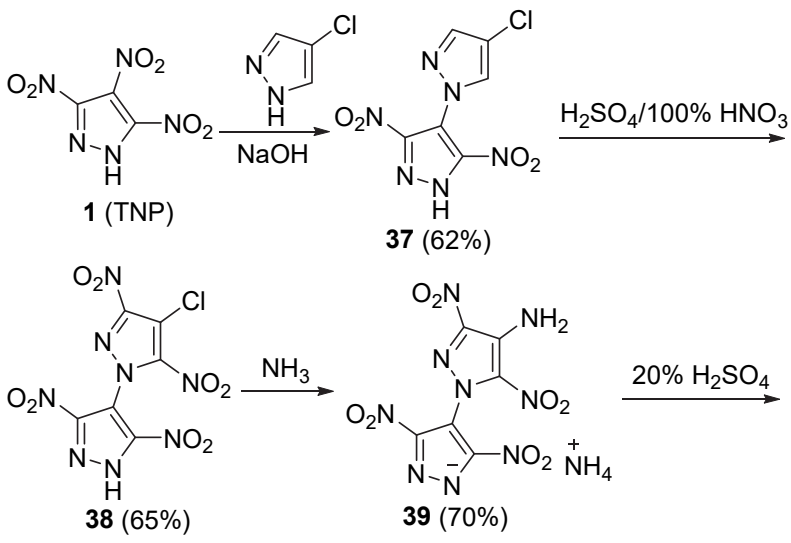

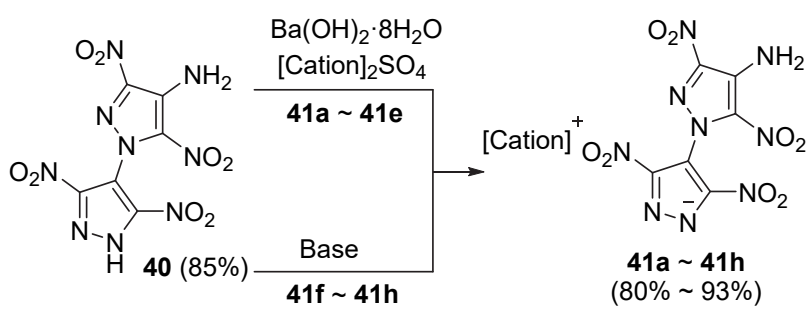

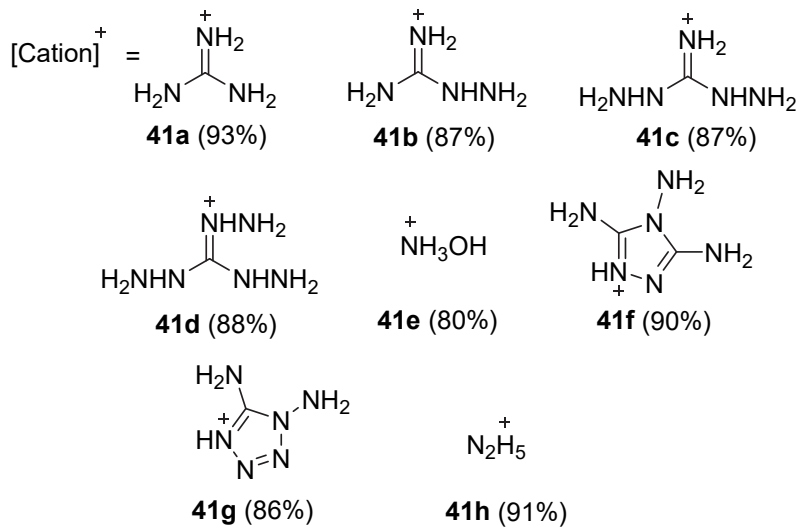

图式 15 4-(4'-氨基-3',5'-二硝基-1'-吡唑)-3,5-二硝基联吡唑含 能离子盐的合成

Scheme 15 Synthesis of energetic salts based on 4-(4'-amino3',5'-dinitro-1'-pyrazol)-3,5-dinitro-1-pyrazole

2016 年, 李川等[63]使用 3,4,5-三硝基吡唑(1, TNP) 与 5-氨基-3-硝基-1,2,4-三唑在强碱性条件下反应, 以 47\%的收率制备了钾盐 42. 该化合物与 $\mathrm{AgNO}_{3}$ 反应, 以 $95 \%$ 的收率得到银盐 43 . 最后, 银盐 43 与不同富 氮碱的盐酸盐发生复分解反应, 以 $71 \% \sim 86 \%$ 的收 率得到含能离子盐 44a 44k (Scheme 16). 它们的密 度介于 $1.65(44 \mathrm{e})$ 到 $1.80(44 \mathrm{i}) \mathrm{g} \cdot \mathrm{cm}^{-3}$ 之间. 热分解温度 介于 215 (44b) 到 $340(\mathbf{4 4 d}){ }^{\circ} \mathrm{C}$ 之间. 爆压和爆速分别介 于 26.5 (44e) 到 35.2 (44i) GPa 和 8236 (44e) 到 9031 (44i) $\mathrm{m} \bullet \mathrm{s}^{-1}$ 之间. 大多数盐撞击感度大于 $40 \mathrm{~J}$, 摩擦感度均大 于 $216 \mathrm{~N}$. 其中 5-肤基四唑盐(44i)的综合性能最佳, 其 密度为 $1.80 \mathrm{~g} \cdot \mathrm{cm}^{-3}$, 热分解温度为 $222{ }^{\circ} \mathrm{C}$, 爆压为 35.2 $\mathrm{GPa}$, 爆速为 $9031 \mathrm{~m} \cdot \mathrm{s}^{-1}$, 撞击感度与摩擦感度分别为
$12 \mathrm{~J}$ 和 $252 \mathrm{~N}$, 优于 RDX $\left(P=38.0 \mathrm{GPa}, D=8983 \mathrm{~m} \cdot \mathrm{s}^{-1}\right.$, $\mathrm{IS}=7.5 \mathrm{~J}, \mathrm{FS}=120 \mathrm{~N}$ ).<smiles>[Y]O[N+](=O)[O-]</smiles>

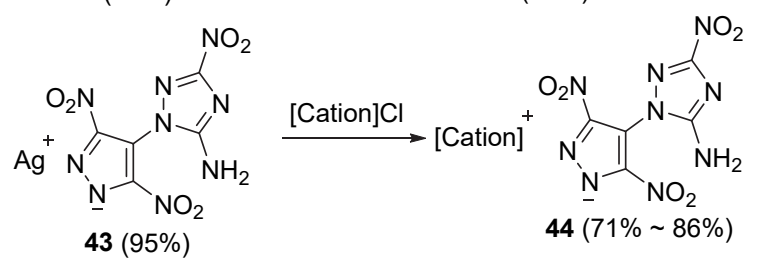

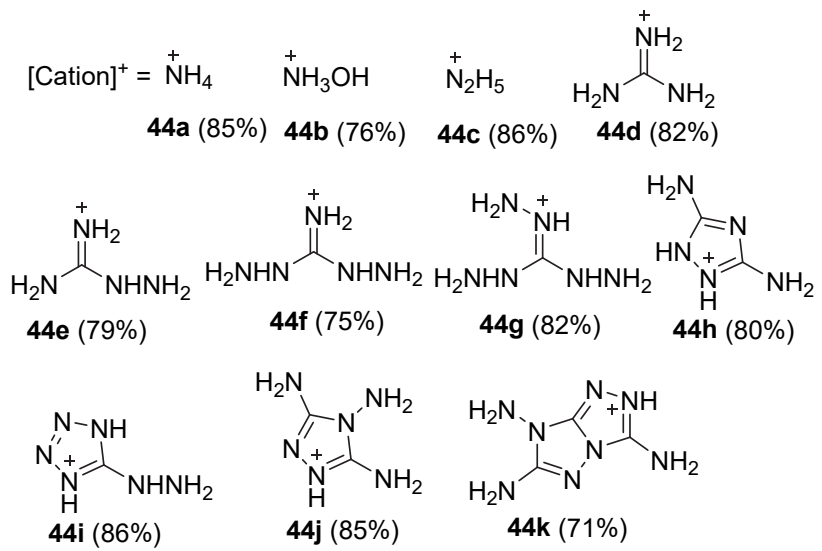

图式 16 1-(3,5-二硝基-1 $H$-吡唑-4-基)-3-硝基-5-氨基-1H1,2,4-三唑含能离子盐的合成

Scheme 16 Synthesis of energetic salts based on 1-(3,5-dinitro$1 H$-pyrazol-4-yl)-3-nitro-1 $H$-1,2,4-triazol-5-amine

2017 年, Kumar 等 ${ }^{[64]}$ 分别以化合物 45a 和 45b 为原 料, 在相转移催化剂四乙基溴化铵(TEAB)的存在下，分 别与氯乙腈反应以 $79 \%$ 和 $81 \%$ 的收率得到化合物 46a 和 46b. 然后, 它们以水为溶液在氯化锌催化下分别与 $\mathrm{NaN}_{3}$ 反应，以 $86 \%$ 和 $93 \%$ 的收率得到化合物 48 和 $\mathbf{5 0}$. 化合物 48 与不同的富氮碱发生酸碱中和反应，以 $80 \% \sim 89 \%$ 的收率得到含能离子盐 $49 \mathbf{a} \sim 49 \mathrm{c}$ (Scheme 17). 它们的热分解温度在 $200(49 b)$ 到 $260(49 a 、 49 c) ~{ }^{\circ} \mathrm{C}$ 之间. 生成焓在 $422.3(49 a)$ 到 $573.8(49 b) \mathrm{kJ}^{\circ} \mathrm{mol}^{-1}$ 之间. 密度介于 $1.65(49 \mathrm{~b})$ 至 $1.75(49 \mathrm{c}) \mathrm{g} \cdot \mathrm{cm}^{-3}$ 之间. 它们的爆 压介于 25.1 (49a) 到 29.8 (49c) GPa 之间, 爆速介于 8153 (49a) 到 $8592(49 \mathrm{c}) \mathrm{m} \cdot \mathrm{s}^{-1}$ 之间. 撞击感度均大于 $40 \mathrm{~J}$, 摩 擦感度均大于 $360 \mathrm{~N}$, 属于不敏感含能材料. 这些盐中, 差弪胺盐(49c)的综合性能最佳, 密度为 $1.75 \mathrm{~g} \cdot \mathrm{cm}^{-3}$, 爆速 和爆压分别为 $8592 \mathrm{~m} \cdot \mathrm{s}^{-1}$ 和 $29.8 \mathrm{GPa}$. 化合物 $\mathbf{5 0}$ 与 $\mathrm{NaN}_{3}$ 反应，再经过酸化以 $85 \%$ 的收率得到叠氮化合物 51, 其与不同的富氮碱发生酸碱中和反应，以 $71 \%$ $86 \%$ 的收率制备得到含能离子盐 $\mathbf{5 2 a} \sim \mathbf{5 2 c}$ (Scheme 
17). 它们的热分解温度在 137 (52b) 到 156 (52a) ${ }^{\circ} \mathrm{C}$ 之 间. 密度介于 $1.64(\mathbf{5 2 a})$ 到 $1.76(52 \mathrm{c}) \mathrm{g} \cdot \mathrm{cm}^{-3}$ 之间. 它们 的爆压介于 25.8 (52a) 到 32.2 (52c) GPa 之间, 爆速介于 8167 (52a) 到 8747 (52c) $\mathrm{m}^{\circ} \mathrm{s}^{-1}$ 之间. 相比于离子盐 49a 49c, 生成焓明显增大, 在 793.0 (52a)至 937.1 $(52 \mathrm{c}) \mathrm{kJ} \cdot \mathrm{mol}^{-1}$ 之间, 但也带来分解温度降低和感度升 高的问题. 撞击感度和摩擦感度分别在 28 (52b)至 40 (52a) $\mathrm{J}$ 和 240 (52b) 至 360 (52a) $\mathrm{N}$ 之间. 在这些含能离 子盐中, 差胺盐 $52 \mathrm{c}$ 的综合性能最佳, 密度为 $1.76 \mathrm{~g} \bullet$ $\mathrm{cm}^{-3}$, 爆速和爆压分别为 $8747 \mathrm{~m} \cdot \mathrm{s}^{-1}$ 和 $32.2 \mathrm{GPa}$,与 $\operatorname{RDX}\left(P=38.0 \mathrm{GPa}, D=8983 \mathrm{~m} \cdot \mathrm{s}^{-1}\right)$ 相当.<smiles>[R]c1c([N+](=O)[O-])n[nH]c1[N+](=O)[O-]</smiles>

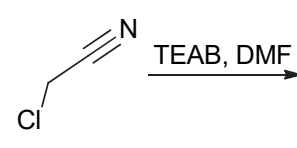

45a: $\mathrm{R}=\mathrm{NH}_{2}$; 45b: $\mathrm{R}=\mathrm{Cl}$<smiles>[R]c1c([N+](=O)[O-])nn(Cc2nnn[nH]2)c1[N+](=O)[O-]</smiles>

48: $\mathrm{R}=\mathrm{NH}_{2}(86 \%)$

50: $\mathrm{R}=\mathrm{Cl}(93 \%)$<smiles>C[13CH]Br</smiles><smiles>Nc1c([N+](=O)[O-])nn(Cc2nnn[o+]2[O-])c1[N+](=O)[O-]</smiles><smiles>O=[N+]([O-])c1nn(Cc2nnn[nH]2)c([N+](=O)[O-])c1Cl</smiles>

(1) $\mathrm{NaN}_{3}$, DMSO (2) $\mathrm{H}_{2} \mathrm{SO}_{4}$ $49 a \sim 49 c(80 \% \sim 89 \%)$

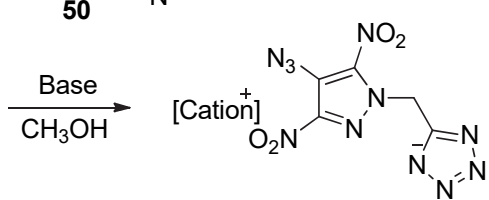
$52 a \sim 52 c(81 \% \sim 90 \%)$

\begin{tabular}{|c|c|c|c|}
\hline$[\text { Cation }]^{+}=$ & $\stackrel{+}{\mathrm{N}} \mathrm{H}_{4}$ & $\stackrel{+}{\mathrm{N}}_{2} \mathrm{H}_{5}$ & $\stackrel{+}{\mathrm{N}} \mathrm{H}_{3} \mathrm{OH}$ \\
\hline & $49 a(89 \%)$ & $49 b(80 \%)$ & $49 c(84 \%)$ \\
\hline & 52a $(90 \%)$ & 52b $(81 \%)$ & 52c $(89 \%)$ \\
\hline
\end{tabular}

图式 17 1-((1H-四唑-5-基)甲基)-4-氨基(或叠氮基)-3,5-二硝 基- $1 H$-吡唑含能离子盐的合成

Scheme 17 Synthesis of energetic salts based on 5-((4-amino (or azido)-3,5-dinitro-1H-pyrazol-1-yl)methyl)- $1 H$-tetrazole

2017 年, 付伟等 ${ }^{[65]}$ 认为两个杂环桥联形成的结构 会提高含能化合物的爆轰性能. 他们以 5-氨基-3,4-二硝 基吡唑(16a) 为原料, 用 $\mathrm{NaOH}$ 将其转化为钠盐, 然后再 与 $\mathrm{CNN}_{3}$ 反应以 $81 \%$ 的收率制备得到化合物 53a. 化合
物 53a 再和 $\mathrm{AgNO}_{3}$ 反应以 $97 \%$ 的收率得到其银盐 54 . 最 后，银盐 54 与富氮卤盐反应，以 $51 \% \sim 91 \%$ 的收率得 到含能离子盐 $55 \mathbf{a} \sim \mathbf{5 5} \mathbf{j}$ (Scheme 18). 它们的密度介于 $1.61(55 \mathrm{e})$ 到 $1.84(\mathbf{5 5 b}) \mathrm{g} \cdot \mathrm{cm}^{-3}$ 之间. 热分解温度在 171 (55b) 到 $270(\mathbf{5 5 j}){ }^{\circ} \mathrm{C}$ 之间. 它们的爆压介于 $25(\mathbf{5 5 e})$ 到 38.3 (55b) GPa 之间, 爆速介于 8229 (55e) 到 9295 (55b) $\mathrm{m} \cdot \mathrm{s}^{-1}$ 之间. 除化合物 55c $(10 \mathrm{~J})$ 和 $55 \mathrm{~g}(12.5 \mathrm{~J})$ 外，其它 盐的撞击感度均大于 $35 \mathrm{~J}$. 多数盐的摩擦感度均大于 200 N. 这些盐中, 羟胺盐 $\mathbf{5 5 b}$ 的密度达到 $1.84 \mathrm{~g} \cdot \mathrm{cm}^{-3}$, 爆轰性能 $\left(P=38.3 \mathrm{GPa}, D=9295 \mathrm{~m} \cdot \mathrm{s}^{-1}\right)$ 优于 $\operatorname{RDX}(P=$ $\left.38.0 \mathrm{GPa}, D=8983 \mathrm{~m} \cdot \mathrm{s}^{-1}\right)$, 与 $\operatorname{HMX}(P=41.5 \mathrm{GPa}, D=$ $\left.9211 \mathrm{~m} \cdot \mathrm{s}^{-1}\right)$ 相当，有望用作 HMX 替代物.

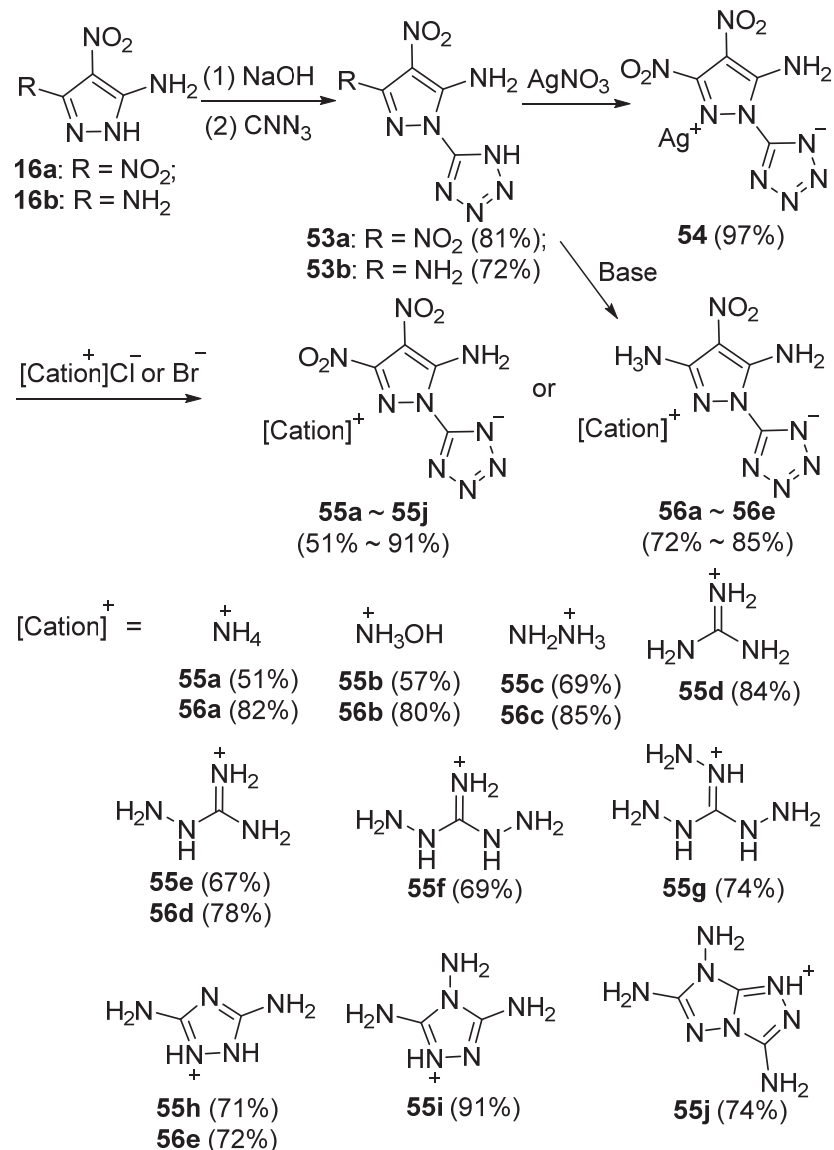

图式 18 5-(5-氨基-3,4-二硝基-1H-吡唑-1-基)四唑和 4-硝基3,5-二氨基-1-(1H-四唑-5-基)吡唑含能离子盐的合成

Scheme 18 Synthesis of energetic salts based on 5-(5-amino3,4-dinitro-1 $H$-pyrazol-1-yl)tetrazole and 3,5-diamino-4-nitro-1(1H-tetrazol-5-yl)pyrazole

2019 年，汤永兴等 ${ }^{[66]}$ 以 4-硝基-3,5-二氨基吡唑 (16b)为原料，使用上述方法以 $72 \%$ 的收率得到化合物 53b. 该化合物与不同的富氮碱发生酸碱中和反应，以 $72 \% \sim 85 \%$ 的收率得到含能离子盐 $56 \mathbf{a} \sim 56 \mathbf{e}$ (Scheme 
18). 它们的密度介于 $1.69(\mathbf{5 6 d})$ 到 $1.78(\mathbf{5 6 b}) \mathrm{g}^{\circ} \mathrm{cm}^{-3}$ 之 间. 热分解温度在 187 (56b) 到 287 (56e) ${ }^{\circ} \mathrm{C}$ 之间. 爆压 和爆速分别介于 23.6 (56e) 到 29.9 (56b) GPa 和 8138 (56e) 到 $8818(\mathbf{5 6 b}) \mathrm{m}^{-\mathrm{s}^{-1}}$ 之间. 所有盐撞击感度均大于 $32 \mathrm{~J}$, 摩擦感度都大于或等于 $360 \mathrm{~N}$. 其中羟胺盐 $\mathbf{5 6 b}$ 的 爆轰性能 $\left(P=29.9 \mathrm{GPa}, D=8818 \mathrm{~m} \bullet \mathrm{s}^{-1}\right)$ 最佳, 与 $\mathrm{RDX}$ $\left(D=8983 \mathrm{~m} \cdot \mathrm{s}^{-1}\right)$ 相当.

\subsection{2 $\mathrm{C}-\mathrm{C}$ 桥联的联环吡唑含能离子盐}

2012 年, Sheremetev 等[67] 以 3-(吡唑-4-基)-4-硝基呋 咱(57)为原料, 采用发烟硫酸/硝酸对其进行硝化, 以 33.3\%的收率得到化合物 $\mathbf{5 8}$. 该化合物分别与不同的碱 发生酸碱中和反应，以 $91 \% \sim 96 \%$ 的收率制备了含能离 子盐 59a 59e (Scheme 19). 它们的热分解温度介于 182 (59d) 到 246 (59b) ${ }^{\circ} \mathrm{C}$ 之间. 通过核磁共振谱、红外光谱 和元素分析对它们进行了结构表征, 但未进行密度和爆 轰性能研究.

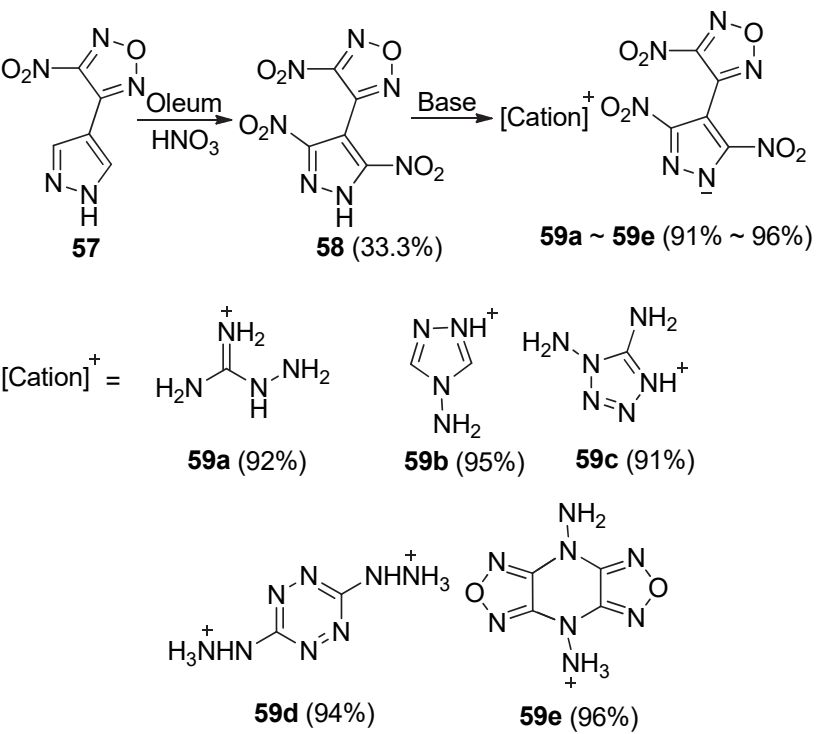

图式 19 3-(3,5-二硝基吡唑-4-基)-4-硝基呋咱含能离子盐的 合成

Scheme 19 Synthesis of energetic salts based on 3-(3,5-dinitropyrazol-4-yl)-4-nitrofurazan

2018 年, 汤永兴等 ${ }^{[68]}$ 以 1,1'-二硝基-3,3'-联吡唑(60) 为原料, 经过苯甲腈重排, 以 $56 \%$ 的收率得到化合物 61. 然后, 使用硝硫混酸对其进行硝化, 以 $81 \%$ 的收率 得到化合物 62. 最后, 化合物 62 与不同的富氮碱进行 酸碱中和反应，以 $82 \% \sim 92 \%$ 的收率得到含能离子盐 63a $\sim 63 \mathrm{~h}$ (Scheme 20). 它们的密度介于 $1.69(63 \mathrm{~d})$ 到

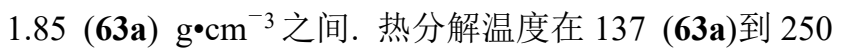
(63h) ${ }^{\circ} \mathrm{C}$ 之间. 爆压介于 25.2 (63d) 到 35.8 (63a) GPa之 间, 爆速介于 $8136(63 \mathrm{~d})$ 到 $8952(63 \mathrm{~g}) \mathrm{m}^{\circ} \mathrm{s}^{-1}$ 之间. 撞击 感度在 8 (63a) 到 $18(63 \mathrm{~h}) \mathrm{J}$ 之间. 大多数盐的摩擦感度 均为 $360 \mathrm{~N}$. 其中羟胺盐 63a $(P=35.8 \mathrm{GPa}, D=8851$ $\left.\mathrm{m} \cdot \mathrm{s}^{-1}\right)$ 和 1,5 -二氨基四唑盐 $63 \mathrm{~g}(P=34.2 \mathrm{GPa}, D=8952$ $\left.\mathrm{m} \cdot \mathrm{s}^{-1}\right)$ 的爆轰性能与RDX $(P=38.0 \mathrm{GPa}, D=8983 \mathrm{~m} \cdot$ $\left.\mathrm{s}^{-1}\right)$ 相当, 感度低于 $\mathrm{RDX}(\mathrm{IS}=7.5 \mathrm{~J}, \mathrm{FS}=120 \mathrm{~N})$, 但它 们的热分解温度偏低.

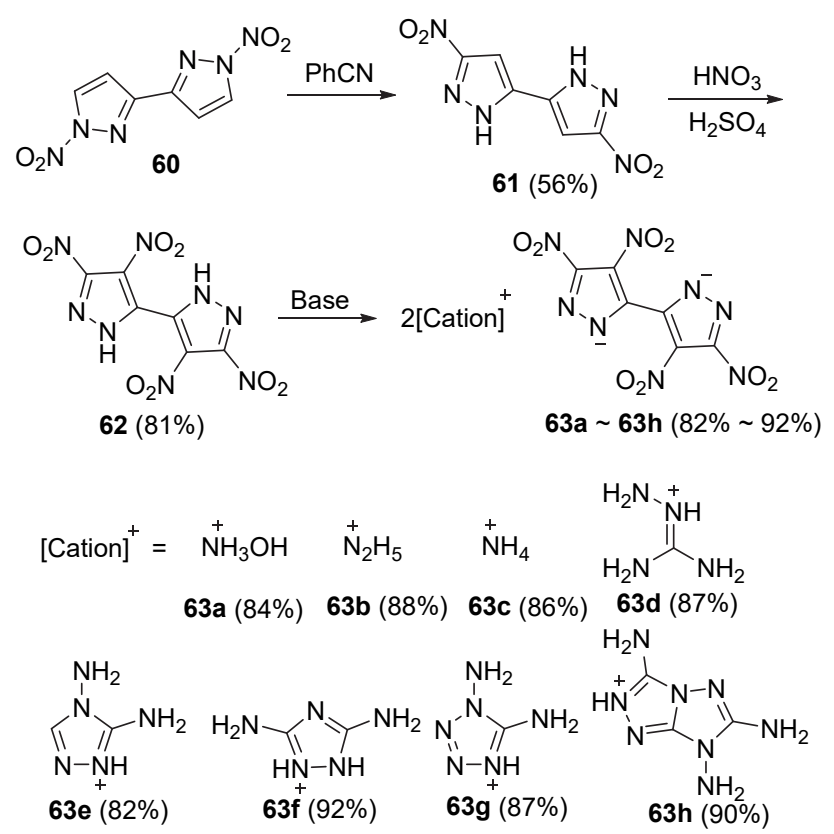

图式 $204,4^{\prime}, 5,5^{\prime}$-四硝基- $2 H, 2^{\prime} H-3,3^{\prime}$-联吡唑含能离子盐的合 成

Scheme 20 Synthesis of energetic salts based on 4,4',5,5'tetranitro- $2 H, 2^{\prime} H-3,3^{\prime}$-bipyrazole

为了设计含有分子内氢键的含能化合物, 2019 年, 徐闵贤等 ${ }^{[69]}$ 以 4 -硝基- $1 H$-吡唑-3,5-二羧酸二甲酯(64)为 原料、甲醇为反应溶剂、甲醇钠为碱，与氨基胍硫酸盐 反应以 $85.7 \%$ 的收率得到化合物 $\mathbf{6 5}$. 然后, 用硝硫混酸 硝化 65 以 $73.6 \%$ 的收率得到化合物 66 . 最后，化合物 66 与不同的富氮碱发生酸碱中和反应，以 $78.1 \%$ $93.2 \%$ 的收率得到含能离子盐 67a $\sim 67 \mathbf{i}$ (Scheme 21). 它 们的热分解温度在 $168.5(67 \mathrm{~g})$ 到 $208.2(67 \mathrm{f}){ }^{\circ} \mathrm{C}$ 之间. 氮 含量在 $48.3 \%(67 \mathrm{a})$ 到 $57.1 \%(67 \mathrm{e})$ 之间. 生成焓在 677.9 (67d)到 $1511.2(67 \mathrm{~h}) \mathrm{kJ} \cdot \mathrm{mol}^{-1}$. 密度介于 $1.71(67 \mathrm{e})$ 到

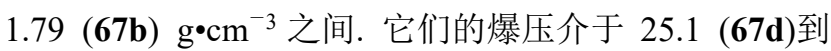
33.6 (67b) GPa 之间, 爆速介于 8117 (67g)到 9077 (67b) $\mathrm{m} \cdot \mathrm{s}^{-1}$ 之间. 除化合物 67a (22.4 J)外，其它盐的撞击感 度均大于 $40 \mathrm{~J}$, 摩擦感度均大于 $360 \mathrm{~N}$. 中性化合物 66 的密度是 $1.92 \mathrm{~g} \cdot \mathrm{cm}^{-3}$, 爆速和爆压分别达到了 $9008 \mathrm{~m} \cdot$ $\mathrm{s}^{-1}$ 和 $35.9 \mathrm{GPa}$, 优于 RDX $(P=38.0 \mathrm{GPa}, D=8983 \mathrm{~m} \cdot$ $\left.\mathrm{s}^{-1}\right)$, 并且感度 $(\mathrm{IS}=20 \mathrm{~J}, \mathrm{FS}=270 \mathrm{~N})$ 比 $\mathrm{RDX}$ 低( $(\mathrm{IS}=7.5$ $\mathrm{J}, \mathrm{FS}=120 \mathrm{~N}$ ). 这些离子盐中, 羟胺盐 $67 \mathrm{~b}$ 的密度是 $1.79 \mathrm{~g} \cdot \mathrm{cm}^{-3}$, 爆速和爆压分别是 $9077 \mathrm{~m} \bullet \mathrm{s}^{-1}$ 和 $33.6 \mathrm{GPa}$, 与 $\mathrm{RDX}$ 相当, 且感度 $(\mathrm{IS}>40 \mathrm{~J}, \mathrm{FS}>360 \mathrm{~N})$ 优于其中性 分子 $(\mathrm{IS}=20 \mathrm{~J}, \mathrm{FS}=270 \mathrm{~N})$ 和 $\mathrm{RDX}(\mathrm{IS}=7.5 \mathrm{~J}, \mathrm{FS}=120$ 
N).<smiles>COC(=O)c1[nH]nc([18OH])c1C(=O)OC</smiles>

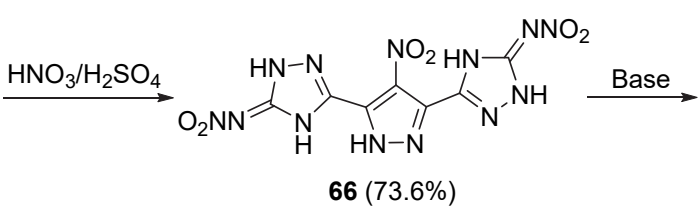<smiles>O=[N+]([O-])c1nc(-c2n[nH]c(-c3n[nH]c([N+](=O)[O-])n3)c2[N+](=O)[O-])n[nH]1</smiles>
$67 \mathbf{a} \sim 67 \mathbf{i}(78.1 \% \sim 93.2 \%)$

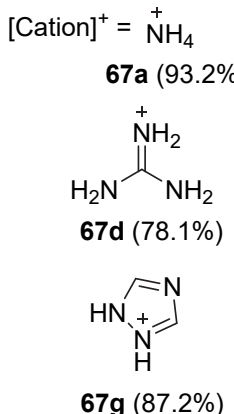
$\stackrel{+}{\mathrm{N}} \mathrm{H}_{3} \mathrm{OH}$ 67b $(89.5 \%)$

$\stackrel{+}{\mathrm{N}_{2}} \mathrm{H}_{5}$<smiles>NNC(N)=[NH2+]</smiles>
67c $(90.2 \%)$<smiles>Nn1cnnc1</smiles>

67h $(88.1 \%)$<smiles>NNC([NH3+])=O</smiles><smiles></smiles>

$67 i(84.3 \%)$

图式 21 ((4-硝基-1H-吡唑-3,5-二基)双(1H-1,2,4-三唑-3,5-二 基))双(硝胺)含能离子盐的合成

Scheme 21 Synthesis of energetic salts based on ((4-nitro- $1 H$ pyrazole-3,5-diyl)bis(1H-1,2,4-triazole-3,5-diyl))bis(nitroamide)

四唑具有极高的氮含量和高达 $200 \mathrm{~kJ} \bullet \mathrm{mol}^{-1}$ 的生成 焓, 2020 年, Benz 等 ${ }^{[70]}$ 使用四唑环对硝基吡唑进行了结 构修饰. 他们以 LLM-116 (7)为原料, 经过重氮化、氰基 取代以 $83 \%$ 的收率制备得到化合物 68, 再与 $\mathrm{NaN}_{3}$ 发生 环化反应, 以 $55 \%$ 的收率得到化合物 69. 最后, 该化合 物 69 与不同的富氮碱反应以 $82 \% \sim 94 \%$ 的收率得到含 能离子盐 70a $\sim 70 \mathrm{~h}$ (Scheme 22). 它们的热分解温度在 168 (70f)到 254 (70c) ${ }^{\circ} \mathrm{C}$ 之间. 密度在 1.68 (70d)到 1.76 (70h) $\mathrm{g} \bullet \mathrm{cm}^{-3}$ 之间, 爆速在 7364 (70h) 到 8648 (70d) m• $\mathrm{s}^{-1}$ 之间. 撞击感度在 2 (70f)到 40 (70h) J 之间. 除化合 物 $70 f(192 \mathrm{~N})$ 外, 其它盐的摩擦感度均大于等于 $360 \mathrm{~N}$. 其中带有两分子结晶水的羟胺盐(70d)密度仅 $1.67 \mathrm{~g} \bullet$ $\mathrm{cm}^{-3}$, 但其爆速仍达 $8648 \mathrm{~m} \cdot \mathrm{s}^{-1}$.

2020 年, Gospodinov 等 ${ }^{[71]}$ 分别以 3,5-二硝基-4,4'-联 吡唑(71)，3,3',5-三硝基-4,4'-联吡唑(73)和 3,3',5,5'-四硝 基-4,4'-联吡唑(75)为原料, 分别与不同的富氮碱发生酸 碱中和反应，制备得到了三个系列含能离子盐 $72 \mathrm{a} \sim$

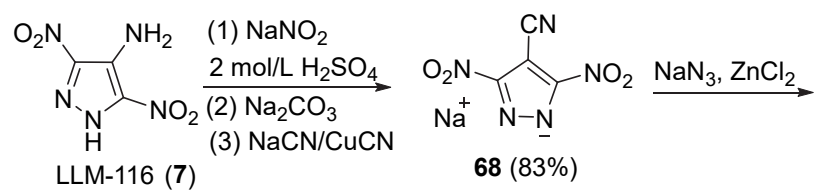

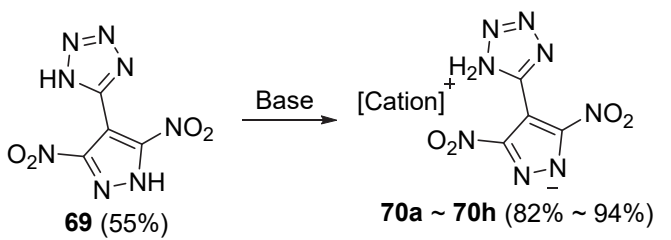

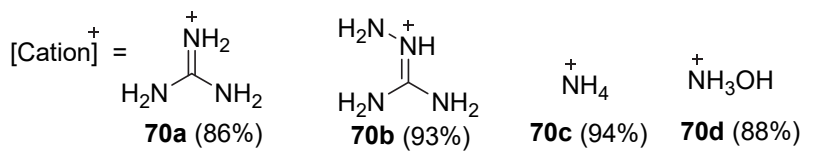

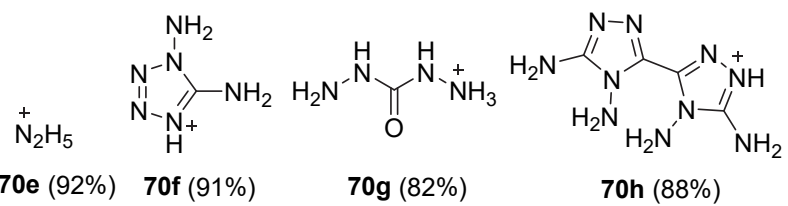

图式 22 5-(3,5-二硝基- $1 H$-吡唑-4-基)- $1 H$-四唑含能离子盐的 合成

Scheme 22 Synthesis of energetic salts based on 5-(3,5-dinitro$1 H$-pyrazol-4-yl)-1 $H$-tetrazole

72c, 74a $\sim 74 \mathrm{e}$ 和 76a 76b (Scheme 23), 收率分别在 $45 \% \sim 70 \% 、 67 \% \sim 99 \%$ 和 $40 \% \sim 100 \%$ 之间. 它们的密 度在 $1.66(\mathbf{7 4 e})$ 到 $1.81(\mathbf{7 6 a}) \mathrm{g} \cdot \mathrm{cm}^{-3}$ 之间, 热分解温度在 201 (76b)到 286 (74b) ${ }^{\circ} \mathrm{C}$ 之间. 爆速在 7563 (74e)到 8673 (76a) $\mathrm{m} \cdot \mathrm{s}^{-1}$ 之间, 爆压在 21.6 (74e) 到 32.8 (76a) $\mathrm{GPa}$ 之间. 撞击感度在 2 (76a) 到 40 (72b) $\mathrm{J}$ 之间. 大多数 离子盐的摩擦感度为 $360 \mathrm{~N}$. 其中羟胺盐 76a 性能 $(D=$ $8673 \mathrm{~m} \cdot \mathrm{s}^{-1}, P=32.8 \mathrm{GPa}$ )最优异, 远优于六硝基芪 (HNS, $D=7612 \mathrm{~m} \cdot \mathrm{s}^{-1}, P=24.3 \mathrm{GPa}$ ), 但其撞击感度高 $(\mathrm{IS}=2 \mathrm{~J})$.

2020 年，马卿等 ${ }^{[72]}$ 使用 4-硝基-3-羧酸吡唑(77)与二 氨基胍盐酸盐反应，以 $84.8 \%$ 的收率制备得到了化合物 78, 其再分别与不同的富氮有机酸发生酸碱中和反应, 以 $80.6 \% \sim 91.1 \%$ 的收率制备得到含能离子盐 79a $\sim 79 \mathrm{~g}$ (Scheme 24), 并对它们进行了全面表征. 它们的分解温 度在 174 (79c)到 289 (79b) ${ }^{\circ} \mathrm{C}$ 之间, 密度在 1.75 (79e)到 $1.82(79 \mathrm{c}) \mathrm{g} \cdot \mathrm{cm}^{-3}$ 之间, 爆速在 7745 (79e) 到 8952 (79g) $\mathrm{m} \cdot \mathrm{s}^{-1}$ 之间，爆压在 $23.8(79 \mathrm{e})$ 到 $30.6(\mathbf{7 9 g}) \mathrm{GPa}$ 之间. 撞 击感度和摩擦感度分别在 18 (79b)到 50 (79g, 79f) $\mathrm{J}$ 和 160 (79b) 到 360 (79f) $\mathrm{N}$ 之间. 其中化合物 79g 的爆轰性 能 $\left(D=8952 \mathrm{~m} \cdot \mathrm{s}^{-1}, P=30.6 \mathrm{GPa}\right)$ 最佳, 优于 $\mathrm{RDX}(P=$ $38.0 \mathrm{GPa}, D=8983 \mathrm{~m} \cdot \mathrm{s}^{-1}$ ), 且感度( IS $=50 \mathrm{~N}, F S=360$ $\mathrm{N})$ 也优于 RDX (IS=7.5 J, FS=120 N), 属于高能不敏 感含能化合物. 


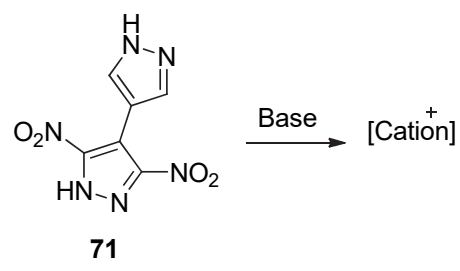<smiles>O=[N+]([O-])c1n[nH]c(-c2cn[nH]c2)c1[N+](=O)[O-]</smiles>
$72(45 \% \sim 70 \%)$<smiles></smiles>
$\stackrel{+}{\mathrm{N}} \mathrm{H}_{4}$

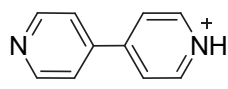
72a $(70 \%)$

72b $(66 \%)$

72c $(45 \%)$

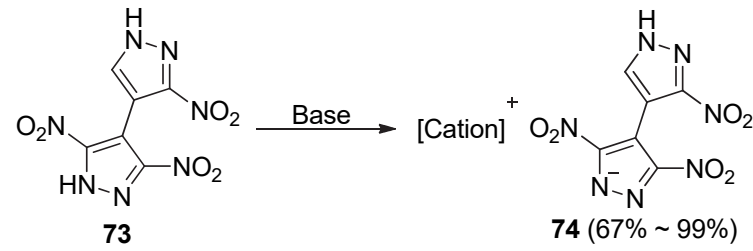

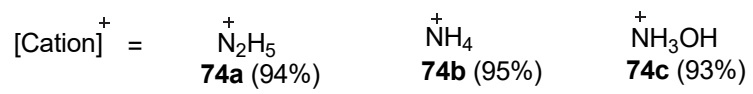

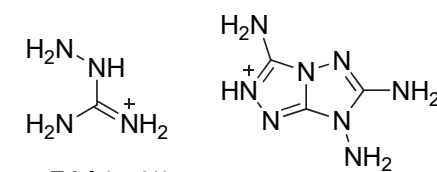

74d (67\%)

$74 \mathrm{e}(99 \%)$<smiles>O=[N+]([O-])c1n[nH]c([N+](=O)[O-])c1-c1c([N+](=O)[O-])n[nH]c1[N+](=O)[O-]</smiles>

[Cation ${ }^{+}=\stackrel{+}{\mathrm{N}} \mathrm{H}_{3} \mathrm{OH}$

$76 a(100 \%)$

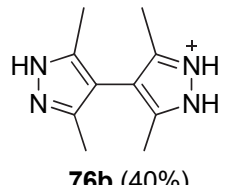

图式 23 3,5-二硝基-4,4'-联吡唑、3,3',5-三硝基-4,4'-联吡唑和 3,3',5,5'-四硝基-4,4'-联吡唑含能离子盐的合成

Scheme 23 Synthesis of the energetic salts based on 3,5-dinitro4,4'-bipyrazole, 3,3',5-trinitro-4,4'-bipyrazole and 3,3',5,5'tetranitro-4,4'-bipyrazole

\subsection{3 $\mathrm{N}=\mathrm{N}$ 桥联的联环吡唑含能离子盐}

Shreeve 等[73]合成的 4,4'-双(二硝基甲基)-3,3'-呋咱 钾盐具有良好的热稳定性 $\left(T_{\mathrm{d}}=229{ }^{\circ} \mathrm{C}\right) .2017$ 年, 张曼 等 ${ }^{[74]}$ 设计并合成了含有偶氮键的吡唑含能盐类耐热炸 药. 他们以 LLM-116 (7)为原料, 在碱性溶液中使用高 锰酸钾为氧化剂, 以 $60 \%$ 的收率得到偶氮化合物 80 , 其 经过酸化以 $43 \%$ 的收率得到化合物 81 . 化合物 81 与不 同的富氮碱发生酸碱中和反应，以 $53 \% \sim 87 \%$ 的收率得 到含能离子盐 $82 \mathrm{e} \sim \mathbf{8 2 g}$ (Scheme 25). 化合物 81 与氢氧 化钡反应后，再与不同的富氮硫酸盐发生复分解反应， 以 $56 \% \sim 83 \%$ 的收率得到含能离子盐 $82 \mathrm{a} \sim 82 \mathrm{~d}$ (Scheme 25). 它们的密度介于 $1.70(\mathbf{8 2 g})$ 到 $1.84(\mathbf{8 2 f}) \mathrm{g} \cdot \mathrm{cm}^{-3}$ 之 间, 除 $82 \mathrm{f}\left(T_{\mathrm{d}}=156{ }^{\circ} \mathrm{C}\right)$ 外, 其它盐的分解温度均大于
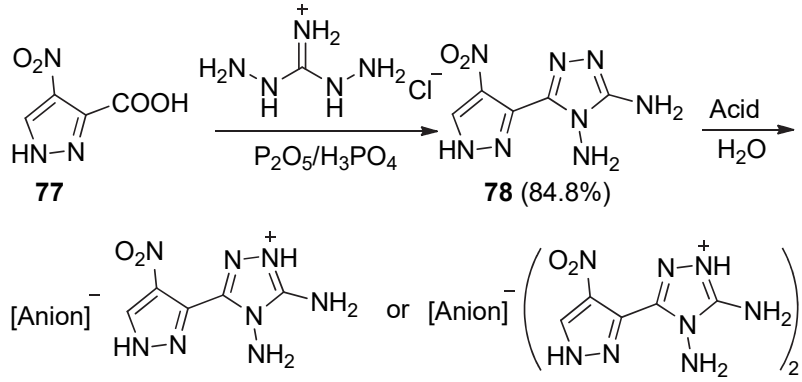
$79 \mathbf{a} \sim 79 \mathrm{~g}(80.6 \% \sim 91.1 \%)$

$$
\begin{aligned}
&\text { [Anion }]=\underset{\mathbf{7 9 a}(90.1 \%)}{\mathrm{NO}_{3}^{-}} \mathrm{ClO}_{4}^{-} \\
& \mathbf{7 9 b}(81 .
\end{aligned}
$$<smiles>O=[N+]([O-])c1nc(-c2nc([N+](=O)[O-])c([N+](=O)[O-])[n-]2)[n-]c1[N+](=O)[O-]</smiles><smiles>O=[N+]([O-])c1cc([N+](=O)[O-])c([O-])c([N+](=O)[O-])c1</smiles><smiles>O=[N+]([O-])c1c([O-])c([N+](=O)[O-])c([N+](=O)[O-])c([N+](=O)[O-])c1O</smiles><smiles>O=c1[n-]c([N+](=O)[O-])n[nH]1</smiles><smiles></smiles>

图式 24 4-硝基-(3,4-二氨基-1,2,4-三唑-5-基)-1 $H$-吡唑含能离 子盐的合成

Scheme 24 Synthesis of energetic salts based on 4-nitro-(3,4diamino-1,2,4-triazol-5-yl)-1 $H$-pyrazole

$180{ }^{\circ} \mathrm{C}$, 其中, 钾盐 $(80)$ 的热分解温度高达 $315{ }^{\circ} \mathrm{C}$. 它 们的爆压介于 26.0 (82g) 到 35.5 (82f) GPa 之间，爆速介 于 $8224(\mathbf{8 2 g})$ 到 $9295(\mathbf{8 2 f}) \mathrm{m} \cdot \mathrm{s}^{-1}$ 之间. 除化合物 82d (2 $\mathrm{J}) 、 82 \mathrm{a}(3 \mathrm{~J})$ 和 $82 \mathrm{e}(7.5 \mathrm{~J})$ 外, 其它盐的撞击感度均大于 $40 \mathrm{~J}$. 多数盐的摩擦感度大于 $190 \mathrm{~N}$. 这些盐中, 肼盐 $82 f$ 的爆压和爆速分别为 $35.5 \mathrm{GPa}$ 和 $9038 \mathrm{~m} \cdot \mathrm{s}^{-1}$, 优于 $\operatorname{RDX}\left(P=38.0 \mathrm{GPa}, D=8983 \mathrm{~m} \bullet \mathrm{s}^{-1}\right)$.

上述联环吡唑离子盐及 TNT、RDX、HMX、CL-20 的理化参数和爆轰性能见表 3 .

\section{3 稠环吡唑含能离子盐}

稠环结构的平面结构有利于提高含能化合物的密 度和降低感度等，因此，其在近期被大量应用于新型含 能化合物的设计与合成中 ${ }^{[75-79]}$. 稠环吡唑含能离子盐的 阴离子是以两个或两个以上的杂环共用环边所形成的 稠环为基本骨架. 与单环吡唑离子盐相比, 稠环吡唑离 子盐具有更高的生成焓、更大的密度和更好的爆轰性能, 同时稠环的共平面还会降低化合物的感度.

1993 年, Shevelev 等 ${ }^{[80]}$ 报道 3,6-二硝基吡唑[4,3-c] 并吡唑(DNPP)的合成, 它的密度为 $1.87 \mathrm{~g} \cdot \mathrm{cm}^{-3}$. 热分解 温度为 $330{ }^{\circ} \mathrm{C}$, 其能量是 $\mathrm{HMX}$ 的 $85 \%$, 撞击感度特性 落高 $H_{50}$ 是 $68 \mathrm{~cm}$, 是高能钝感化合物的代表.

2014 年, 张嘉恒等 ${ }^{[81]}$ 以乙酰丙酮 $(83)$ 为原料, 经过 肟化、还原、重氮化、硝化等八步反应制备了 3,6-二硝 


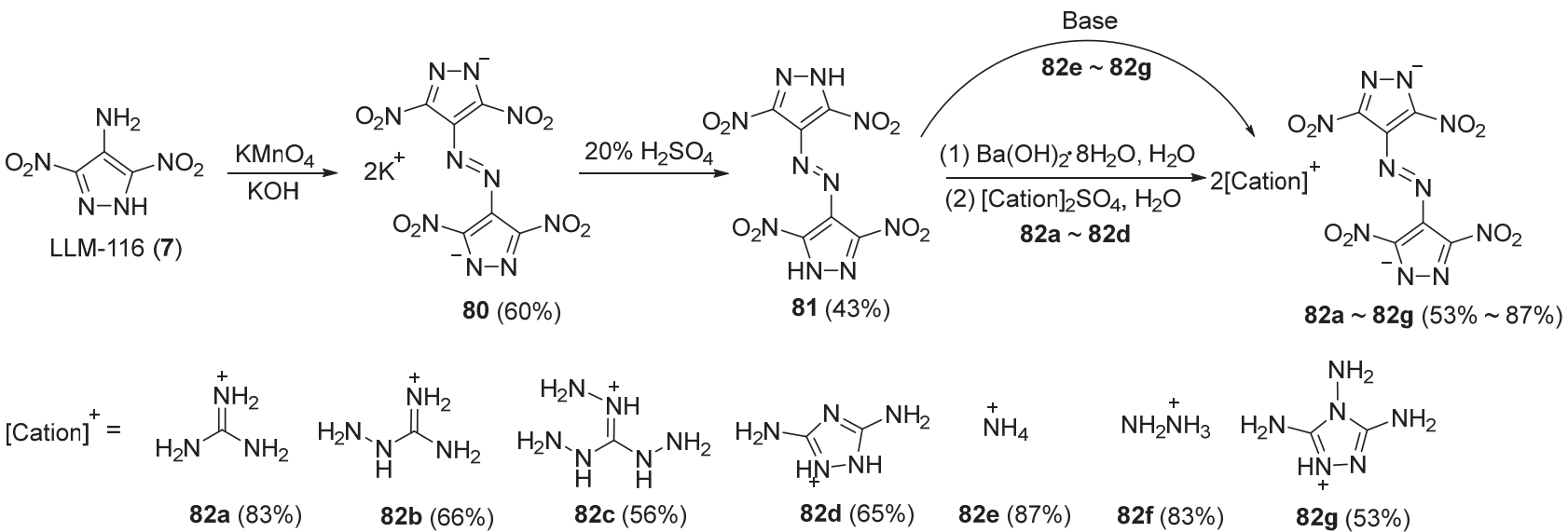

图式 $25(E)-1,2$-双(3,5-二硝基- $1 H$-吡唑-4-基)二氮烯含能离子盐的合成

Scheme 25 Synthesis of energetic salts based on (E)-1,2-bis(3,5-dinitro-1 $H$-pyrazol-4-yl)diazene

表 3 联环吡唑离子盐的理化参数和爆轰性能

Table 3 Physicochemical properties and energetic properties of energetic salts based on bicyclic pyrazoles

\begin{tabular}{|c|c|c|c|c|c|c|c|c|}
\hline Compd. & $T_{\mathrm{m}}{ }^{a} /{ }^{\circ} \mathrm{C}$ & $T_{\mathrm{d}}^{b} /{ }^{\circ} \mathrm{C}$ & $d^{c} /\left(\mathrm{g} \cdot \mathrm{cm}^{-3}\right)$ & $\Delta_{\mathrm{f}} H^{d} /\left(\mathrm{kJ} \cdot \mathrm{mol}^{-1}\right) /\left(\mathrm{kJ} \cdot \mathrm{g}^{-1}\right)$ & $P^{e} / \mathrm{GPa}$ & $D^{f} /\left(\mathrm{m}^{\prime} \mathrm{s}^{-1}\right)$ & $\mathrm{IS}^{g} / \mathrm{J}$ & $\mathrm{FS}^{h} / \mathrm{N}$ \\
\hline 39 & - & 262 & 1.88 & $274.7 / 0.79$ & 34.6 & 8615 & $>40$ & - \\
\hline $41 \mathrm{a}$ & - & 228 & 1.73 & $246.5 / 0.63$ & 27.3 & 8041 & $>40$ & - \\
\hline $41 \mathrm{~b}$ & 249 & 272 & 1.67 & $506.4 / 1.26$ & 27.1 & 8088 & $>40$ & - \\
\hline $41 \mathrm{c}$ & 210 & 272 & 1.71 & $448.8 / 1.07$ & 27.9 & 8201 & $>40$ & - \\
\hline 41d & 212 & 266 & 1.72 & $558.0 / 1.29$ & 29.0 & 8339 & $>40$ & - \\
\hline $41 \mathrm{e}$ & - & 259 & 1.75 & $331.2 / 0.91$ & 31.1 & 8330 & $>40$ & - \\
\hline $41 f$ & 247 & 297 & 1.82 & $557.0 / 1.26$ & 31.0 & 8449 & $>40$ & - \\
\hline $41 \mathrm{~g}$ & 166 & 261 & 1.72 & $700.4 / 1.63$ & 28.9 & 8231 & $>40$ & - \\
\hline $41 \mathrm{~h}$ & - & 260 & 1.80 & $428.1 / 1.19$ & 32.8 & 8536 & $>40$ & - \\
\hline $44 a$ & 132 & 285 & 1.73 & $622.8 / 2.06$ & 31.6 & 8621 & $>40$ & $>360$ \\
\hline $44 b$ & - & 215 & 1.76 & $709.9 / 2.23$ & 34.4 & 8832 & 33 & 252 \\
\hline $44 c$ & - & 241 & 1.74 & $811.4 / 2.56$ & 32.9 & 8798 & $>40$ & $>360$ \\
\hline 44d & - & 340 & 1.78 & $624.1 / 1.81$ & 31.1 & 8660 & $>40$ & $>360$ \\
\hline $44 \mathrm{e}$ & - & 281 & 1.65 & $728.9 / 2.03$ & 26.5 & 8236 & $>40$ & $>360$ \\
\hline $44 f$ & 233 & 262 & 1.70 & $831.7 / 2.22$ & 28.9 & 8541 & 27 & 240 \\
\hline $44 \mathrm{~g}$ & - & 242 & 1.71 & $941.4 / 2.42$ & 30.0 & 8685 & 20 & 216 \\
\hline $44 \mathrm{~h}$ & - & 279 & 1.72 & $828.3 / 2.16$ & 28.0 & 8363 & $>40$ & 252 \\
\hline $44 i$ & - & 222 & 1.80 & $1211.7 / 3.15$ & 35.2 & 9031 & 12 & 252 \\
\hline $44 j$ & - & 292 & 1.74 & $944.8 / 2.37$ & 29.5 & 8555 & $>40$ & $>360$ \\
\hline $44 k$ & - & 303 & 1.77 & $1166.1 / 2.65$ & 30.5 & 8647 & 20 & $>360$ \\
\hline $49 a$ & 186 & 260 & 1.68 & $422.3 / 1.55$ & 25.1 & 8153 & $>40$ & $>360$ \\
\hline $49 b$ & 192 & 200 & 1.65 & $573.8 / 2.00$ & 25.6 & 8264 & $>40$ & $>360$ \\
\hline $49 c$ & 224 & 260 & 1.75 & $470.2 / 1.62$ & 29.8 & 8592 & $>40$ & $>360$ \\
\hline $52 a$ & - & 156 & 1.64 & $793.0 / 2.66$ & 25.8 & 8167 & $>40$ & $>360$ \\
\hline $52 b$ & - & 137 & 1.72 & $937.1 / 2.99$ & 29.7 & 8640 & 28 & 240 \\
\hline $52 \mathrm{c}$ & - & 151 & 1.76 & $834.3 / 2.66$ & 32.2 & 8747 & 32 & $>360$ \\
\hline $55 a$ & - & 216 & 1.72 & $763.6 / 2.96$ & 31.3 & 8745 & 40 & 360 \\
\hline $55 b$ & - & 171 & 1.84 & $805.8 / 2.94$ & 38.3 & 9295 & 35 & 216 \\
\hline $55 c$ & - & 196 & 1.77 & $910.0 / 3.15$ & 35.0 & 9162 & 10 & 160 \\
\hline 55d & - & 257 & 1.74 & $729.1 / 2.43$ & 29.6 & 8668 & 40 & 360 \\
\hline $55 e$ & 195 & 221 & 1.61 & $834.7 / 2.65$ & 25.4 & 8229 & 37.5 & 252 \\
\hline $55 f$ & 178 & 216 & 1.70 & $935.9 / 2.83$ & 29.3 & 8712 & 30 & 240 \\
\hline $55 \mathrm{~g}$ & 188 & 208 & 1.66 & $1049.2 / 3.04$ & 28.6 & 8657 & 12.5 & 216 \\
\hline $55 \mathrm{~h}$ & - & 216 & 1.76 & $930.3 / 2.73$ & 29.5 & 8649 & 40 & 324 \\
\hline $55 \mathbf{i}$ & - & 239 & 1.74 & $1049.8 / 2.96$ & 29.6 & 8701 & 35 & 360 \\
\hline $55 \mathbf{j}$ & - & 270 & 1.72 & $1275.2 / 3.23$ & 28.6 & 8562 & 40 & 360 \\
\hline
\end{tabular}




\begin{tabular}{|c|c|c|c|c|c|c|c|c|}
\hline Compd. & $T_{\mathrm{m}}{ }^{a} /{ }^{\circ} \mathrm{C}$ & $T_{\mathrm{d}}^{b} /{ }^{\circ} \mathrm{C}$ & $d^{c} /\left(\mathrm{g} \cdot \mathrm{cm}^{-3}\right)$ & 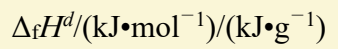 & $P^{e} / \mathrm{GPa}$ & $D^{f} /\left(\mathrm{m} \cdot \mathrm{s}^{-1}\right)$ & $\mathrm{IS}^{g} / \mathrm{J}$ & $\mathrm{FS}^{h} / \mathrm{N}$ \\
\hline $56 a$ & - & 229 & 1.75 & $547.1 / 2.25$ & 28.9 & 8801 & 35 & 360 \\
\hline $56 b$ & - & 187 & 1.78 & $445.0 / 1.82$ & 29.9 & 8818 & 32 & 360 \\
\hline $56 c$ & - & 251 & 1.70 & $399.1 / 1.75$ & 24.9 & 8286 & 40 & $>360$ \\
\hline 56d & - & 224 & 1.69 & $485.5 / 1.70$ & 23.9 & 8244 & 40 & $>360$ \\
\hline $56 e$ & - & 287 & 1.72 & $337.7 / 1.03$ & 23.6 & 8138 & 40 & $>360$ \\
\hline $63 a$ & - & 137 & 1.85 & $220.6 / 0.58$ & 35.8 & 8851 & 8 & 240 \\
\hline $63 b$ & 94 & 155 & 1.77 & $220.9 / 0.56$ & 31.5 & 8670 & 10 & 240 \\
\hline $63 \mathrm{c}$ & - & 193 & 1.76 & $116.2 / 0.33$ & 29.4 & 8343 & 10 & 240 \\
\hline 63d & - & 196 & 1.70 & $353.3 / 0.76$ & 25.2 & 8136 & 15 & 360 \\
\hline $63 e$ & 185 & 186 & 1.75 & $791.9 / 1.55$ & 27.3 & 8306 & 16 & 360 \\
\hline $63 \mathrm{f}$ & - & 206 & 1.76 & $565.4 / 1.10$ & 26.5 & 8219 & 12 & 360 \\
\hline $63 \mathrm{~g}$ & 187 & 193 & 1.81 & $1359.4 / 2.64$ & 34.2 & 8952 & 10 & 360 \\
\hline $63 \mathrm{~h}$ & - & 250 & 1.80 & $1269.7 / 2.04$ & 28.9 & 8542 & 18 & 360 \\
\hline $67 a$ & - & 187 & 1.76 & 711.4/1.77 & 30.0 & 8680 & $>40$ & $>360$ \\
\hline $67 \mathrm{~b}$ & - & 171 & 1.79 & $842.0 / 1.92$ & 33.6 & 9077 & $>40$ & $>360$ \\
\hline $67 \mathrm{c}$ & - & 187 & 1.73 & $1062.4 / 2.46$ & 30.2 & 8759 & $>40$ & $>360$ \\
\hline $67 d$ & - & 195 & 1.71 & $677.9 / 1.40$ & 25.1 & 8193 & $>40$ & $>360$ \\
\hline $67 e$ & - & 191 & 1.71 & $1068.7 / 2.07$ & 27.3 & 8502 & $>40$ & $>360$ \\
\hline $67 f$ & - & 208 & 1.75 & $1014.6 / 1.85$ & 29.7 & 8705 & 22.4 & $>360$ \\
\hline $67 \mathrm{~g}$ & - & 169 & 1.72 & $1300.5 / 2.58$ & 25.7 & 8117 & $>40$ & $>360$ \\
\hline $67 \mathrm{~h}$ & - & 176 & 1.72 & $1511.2 / 2.39$ & 25.9 & 8143 & $>40$ & $>360$ \\
\hline $67 i$ & - & 190 & 1.74 & $1270.5 / 2.84$ & 26.0 & 8159 & $>40$ & $>360$ \\
\hline $70 \mathrm{~b}$ & - & 209 & 1.71 & $432.7 / 1.44$ & 24.3 & 8062 & 20 & 360 \\
\hline $70 \mathrm{c}$ & - & 254 & 1.67 & $348.4 / 1.25$ & 28.3 & 8431 & 5 & 360 \\
\hline 70d & - & 197 & 1.69 & $425.1 / 1.44$ & 31.0 & 8648 & 10 & 360 \\
\hline $70 f$ & - & 168 & 1.76 & $820.6 / 2.52$ & 27.9 & 8441 & 2 & 192 \\
\hline $70 \mathrm{~h}$ & - & 240 & 1.73 & 298.0/0.71 & 18.8 & 7364 & 40 & $>360$ \\
\hline $72 a$ & - & 250 & 1.68 & $405.1 / 1.58$ & 22.4 & 7714 & 8 & $>360$ \\
\hline $74 a$ & - & 218 & 1.75 & $390.9 / 1.30$ & 27.2 & 8223 & 15 & $>360$ \\
\hline $74 \mathrm{~b}$ & 251 & 286 & 1.68 & $-50.4 /-0.17$ & 23.0 & 7689 & 40 & $>360$ \\
\hline $74 c$ & - & 230 & 1.76 & $303.7 / 1.00$ & 28.6 & 8271 & 10 & $>360$ \\
\hline $74 \mathrm{e}$ & - & 240 & 1.66 & $740.7 / 1.75$ & 21.6 & 7563 & 10 & $>360$ \\
\hline $76 a$ & - & 201 & 1.81 & $295.7 / 0.85$ & 32.8 & 8673 & 2 & 216 \\
\hline $79 a$ & - & 225 & 1.77 & $291.0 / 1.07$ & 28.6 & 8516 & 25 & 168 \\
\hline $79 \mathrm{~b}$ & 220 & 289 & 1.81 & $287.3 / 0.92$ & 29.0 & 8257 & 18 & 160 \\
\hline $79 \mathrm{c}$ & - & 174 & 1.82 & $1404.5 / 2.68$ & 30.4 & 8641 & 25 & 240 \\
\hline 79d & 240 & 254 & 1.81 & $153.0 / 0.35$ & 26.4 & 8109 & 20 & 240 \\
\hline $79 \mathrm{e}$ & - & 202 & 1.75 & $-196.3 /-0.42$ & 23.8 & 7745 & 25 & 288 \\
\hline $79 f$ & - & 213 & 1.76 & $346.3 / 1.02$ & 25.7 & 8228 & 50 & $>360$ \\
\hline $79 \mathrm{~g}$ & - & 261 & 1.81 & $1566.2 / 2.65$ & 30.6 & 8952 & 50 & 360 \\
\hline 80 & - & 315 & 2.15 & $45.7 / 0.11$ & 31.1 & 8275 & 1.5 & 60 \\
\hline $82 a$ & - & 304 & 1.78 & $327.4 / 0.71$ & 28.0 & 8391 & $>40$ & $>360$ \\
\hline $82 b$ & - & 195 & 1.79 & $535.4 / 1.09$ & 29.5 & 8632 & $>40$ & 216 \\
\hline $82 c$ & - & 183 & 1.73 & $1013.5 / 1.84$ & 29.6 & 8731 & 2 & 54 \\
\hline 82d & - & 206 & 1.80 & $767.4 / 1.42$ & 28.6 & 8461 & $>40$ & $>360$ \\
\hline $82 e$ & - & 257 & 1.81 & $329.1 / 0.87$ & 32.2 & 8638 & 7.5 & $>360$ \\
\hline $82 f$ & - & 156 & 1.84 & $634.5 / 1.56$ & 35.5 & 9038 & 4 & 192 \\
\hline $82 \mathrm{~g}$ & - & 244 & 1.70 & $1040.1 / 1.82$ & 26.0 & 8224 & 37.5 & $>360$ \\
\hline $\mathrm{TNT}^{i}$ & 81 & 290 & 1.65 & $-55.5 /-0.24$ & 23.5 & 7459 & 15 & 353 \\
\hline $\mathrm{RDX}^{i}$ & 205 & 210 & 1.81 & $86.3 / 0.39$ & 38.0 & 8983 & 7.5 & 120 \\
\hline $\mathrm{HMX}^{i}$ & 275 & 279 & 1.90 & $116.1 / 0.39$ & 41.5 & 9221 & 7 & 112 \\
\hline CL-20 ${ }^{i}$ & - & 215 & 2.04 & $365.4 / 0.83$ & 46.7 & 9455 & 4 & 48 \\
\hline
\end{tabular}

${ }^{a}$ Melting point. ${ }^{b}$ Decomposition temperature. ${ }^{c}$ Density. ${ }^{d}$ Calculated molar enthalpy of formation. ${ }^{e}$ Detonation pressure. ${ }^{f}$ Detonation velocity. ${ }^{g}$ Impact sensitivity. ${ }^{h}$ Friction sensitivity. ${ }^{i}$ Ref. [4]. 
基吡唑 $[4,3-c]$ 并吡唑 $(85, \mathrm{DNPP})$, 总收率为 9.3\%. DNPP 与富氮碱发生酸碱中和反应制备了含能离子盐 $86 \mathrm{a} \sim$ 86e (Scheme 26), 但没有给出具体收率数据. DNPP 与氢 氧化钠反应制备的钠盐 $86 f$ 与富氮盐酸盐等发生复分解 反应制备得到了含能离子盐 86g 86k (Scheme 26). 它 们的热分解温度在 $209(\mathbf{8 6 j})$ 到 $328(\mathbf{8 6 a}){ }^{\circ} \mathrm{C}$ 之间, 密度 在 $1.67(\mathbf{8 6 e})$ 到 $1.82(\mathbf{8 6 b}) \mathrm{g} \cdot \mathrm{cm}^{-3}$ 之间, 它们的爆压和爆 速分别在 22.5 (86g)到 35.4 (86b) GPa 和 7948 (86g) 到 9005 (86b) $\mathrm{m} \cdot \mathrm{s}^{-1}$ 之间. 其中, 差弪胺盐 $86 b(D=9005 \mathrm{~m} \cdot$ $\left.\mathrm{s}^{-1}, P=35.4 \mathrm{GPa}\right)$ 和肼盐 $86 \mathrm{c}\left(D=8860 \mathrm{~m} \cdot \mathrm{s}^{-1}, P=30.3\right.$ $\mathrm{GPa})$ 的爆轰性能远高于 TNT $\left(D=6881 \mathrm{~m} \cdot \mathrm{s}^{-1}, P=30.3\right.$ $\mathrm{GPa})$ ，与 $\mathrm{RDX}\left(P=38.0 \mathrm{GPa}, D=8983 \mathrm{~m} \cdot \mathrm{s}^{-1}\right)$ 相当. 对 于 DNPP 的胍盐 $(86 g)$ 、氨基胍盐 $(86 h)$ 、二氨基胍盐 $(86 \mathbf{i})$ 、 三氨基胍盐 $(\mathbf{8 6 j})$, 随着取代氨基个数的增多, 氮含量增 多, 生成焓增加, 爆轰性能增加, 爆压从 $22.5 \mathrm{GPa}$ 增加 到 $29.9 \mathrm{GPa}$ ，爆速从 $7948 \mathrm{~m} \cdot \mathrm{s}^{-1}$ 增加到 $8814 \mathrm{~m} \cdot \mathrm{s}^{-1}$. 但 热稳定性有所下降, 热分解温度从 $324{ }^{\circ} \mathrm{C}$ 下降到 $215{ }^{\circ} \mathrm{C}$.

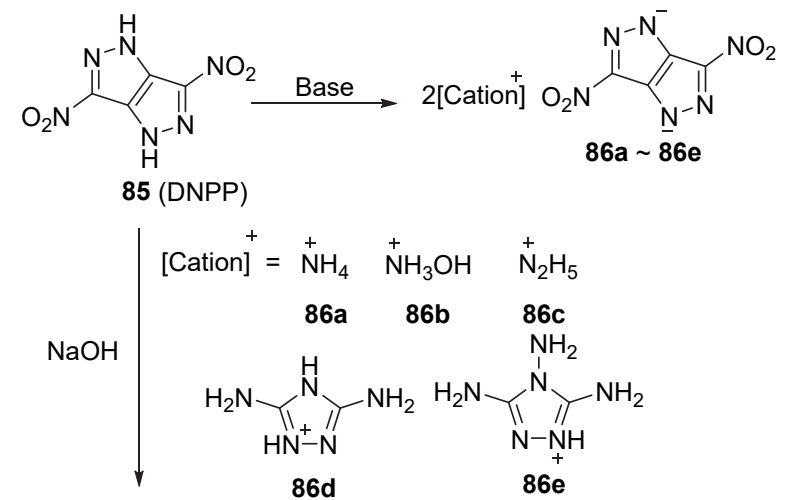

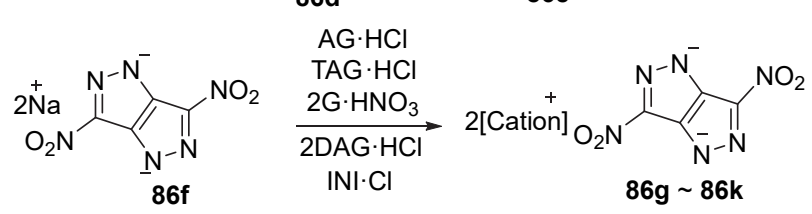<smiles>NNC(=[NH2+])NNC(N)=[NH+]N</smiles><smiles></smiles>

图式 26 3,6-二硝基吡唑 [4,3-c]并吡唑含能离子盐的合成 Scheme 26 Synthesis of energetic salts based on 3,6-dinitropyrazolo[4,3-c]pyrazole

2016 年, 尹平等 ${ }^{[82]}$ 先尝试用 4-氯-3,5-二硝基吡唑 $(87)$ 与水合肼反应制备稠环化合物, 但未得到目标产物. 后以 1-甲基-4-氯-3,5-二硝基吡唑(87)与水合肼反应, 得
到了化合物 88 , 其经酸化后再与一系列富氮碱反应，以 90\% 96\%的收率制备得到含能离子盐 $90 \mathrm{a} \sim 90 \mathrm{e}$ (Scheme 27). 它们的密度在 1.62 (90c)到 1.76 (90b) g• $\mathrm{cm}^{-3}$ 之间, 热分解温度在 112 (90b)到 192 (90c) ${ }^{\circ} \mathrm{C}$ 之间. 爆压和爆速分别在 22.5 (90c)到 31.9 (90b) GPa 之间和 7911 (90c)到 8859 (90b) $\mathrm{m} \cdot \mathrm{s}^{-1}$ 之间. 其中, 羟胺盐 $(90 b)$ 的爆轰性能最佳, 分别为 $31.9 \mathrm{GPa}$ 和 $8859 \mathrm{~m} \bullet \mathrm{s}^{-1}$, 与 $\operatorname{RDX}\left(P=38.0 \mathrm{GPa}, D=8983 \mathrm{~m} \cdot \mathrm{s}^{-1}\right)$ 相当. 除了羟胺盐 $90 \mathrm{~b}$ 的撞击感度 $(8 \mathrm{~J})$ 较高外, 其它盐的撞击感度都大于 $15 \mathrm{~J}$, 优于 $\operatorname{RDX}(7 \mathrm{~J})$.
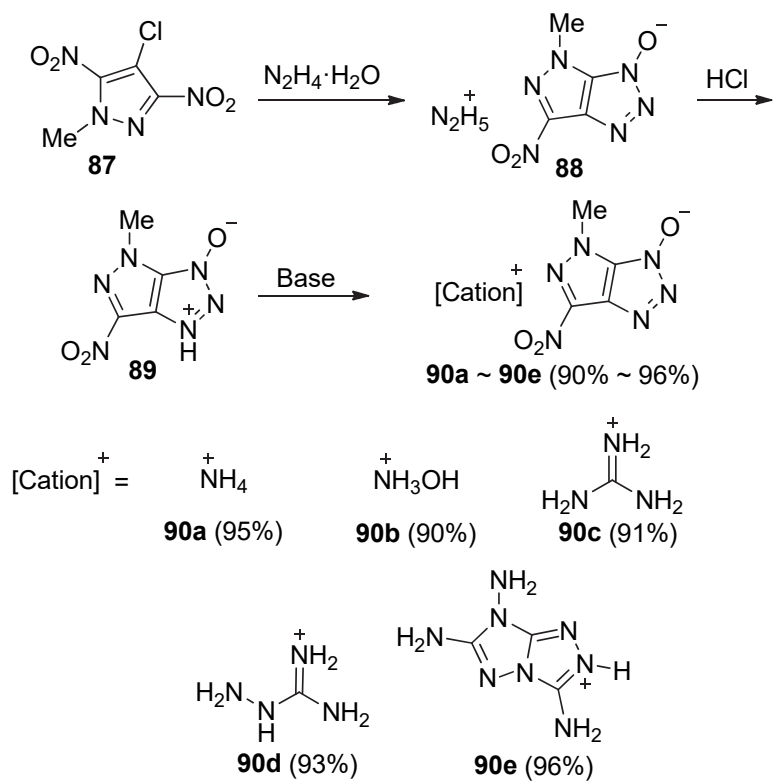

图式 27 1-羟基-4-甲基-6-硝基吡唑 $[3,4-d][1,2,3]$ 三唑离子盐 的合成

Scheme 27 Synthesis of energetic salts based on 1-hydroxy-4methyl-6-nitropyrazolo[3,4- $d][1,2,3]$ triazole

2016 年，尹平等 ${ }^{[83]}$ 以对甲苯磺酰羟胺(THA)为胺化 试剂、1,8-二氮杂二环十一碳-7-烯(DBU)为脱酸剂, 对 3,6 -二硝基吡唑 $[4,3-c]$ 并吡唑 (85, DNPP)进行胺化，以 $82 \%$ 的收率制备了化合物 91. 该化合物经过硝硫混酸硝 化以 $92.8 \%$ 的收率制得硝胺化合物 92. 最后, 其与富氮 碱酸碱进行酸碱中和，以 $65 \%$ ～93\%的收率制备了含能 离子盐 93a 93h (Scheme 28). 它们的密度在 $1.68(93 d)$ 到 $1.88(93 \mathrm{a}) \mathrm{g} \cdot \mathrm{cm}^{-3}$ 之间, 热分解温度在 $141(\mathbf{9 3 e})$ 到 203 (93h) ${ }^{\circ} \mathrm{C}$ 之间. 它们的爆压在 26.9 (93d)到 41.3 (93a) GPa 之间, 爆速在 8295 (93d) 到 9507 (93a) $\mathrm{m} \bullet \mathrm{s}^{-1}$ 之间. 撞击感度和摩擦感度分别介于 5 (93c)到 35 (93d) $\mathrm{J}$ 和 60 (93c) 到 $360($ (93f) N. 其中羟胺盐 93a 的密度达到

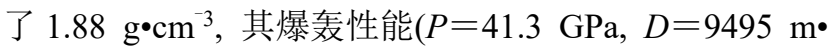
$\left.\mathrm{s}^{-1}\right)$ 优于 HMX $\left(P=41.5 \mathrm{GPa}, D=9221 \mathrm{~m} \cdot \mathrm{s}^{-1}\right) .2019$ 年, 李亚南等 ${ }^{[84]}$ 进一步制备了氨基嫝盐 93i, 氮含量、爆轰 
性能 $\left(P=32.6 \mathrm{GPa}, D=8516 \mathrm{~m} \cdot \mathrm{s}^{-1}\right)$ 明显高于 DNPP, 与 $\operatorname{RDX}\left(P=38.0 \mathrm{GPa}, D=8983 \mathrm{~m} \cdot \mathrm{s}^{-1}\right)$ 相当.

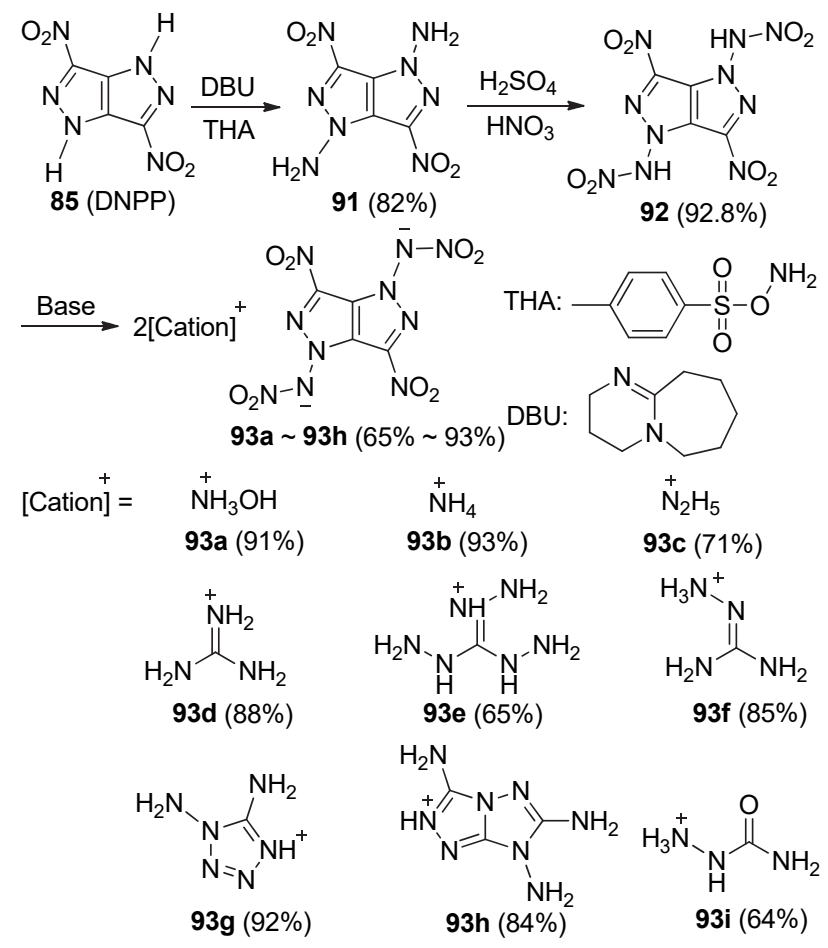

图式 28 1,4-二硝胺-3,6-二硝基吡唑[4,3-c]并吡唑含能离子盐 的合成

Scheme 28 Synthesis of energetic salts based on 1,4-dinitramino-3,6-dinitropyrazolo[4,3-c]pyrazoles

四唑具有很高的生成焓 $\left(4.77 \mathrm{~kJ} \cdot \mathrm{g}^{-1}\right)$ 及热稳定性. 2019 年, 夏红蕾等 ${ }^{[85]}$ 在 3,6-二硝基吡唑[4,3-c]并吡唑 (85, DNPP)上引入四唑, 合成了 3,6-二硝基-1,4-二(1H四唑-5-基)-吡唑并[4,3-c]吡唑(95, DNTPP), 其与一系列 富氮碱反应, 制备得到了含能离子盐 96a $\sim 96 \mathrm{e}$ (Scheme 27), 收率在 $44.0 \%$ 到 $84.0 \%$ 之间. 它们的密度在 1.61

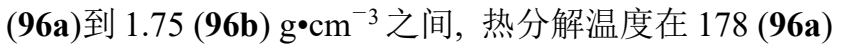
到 299 (96d) ${ }^{\circ} \mathrm{C}$ 之间, 爆压在 22.4 (96d) 到 31.3 (96b) $\mathrm{GPa}$ 之间, 爆速在 8023 (96d)到 9082 (96b) $\mathrm{m}^{\circ} \mathrm{s}^{-1}$ 之间. 多数化合物的撞击感度大于 $27 \mathrm{~J}$, 摩擦感度大于 $320 \mathrm{~N}$. 其中, 肼盐 $96 \mathbf{b}$ 的爆轰性能 $(P=31.3 \mathrm{GPa}, D=9082 \mathrm{~m}$ $\left.\mathrm{s}^{-1}\right)$ 最优, 与 $\operatorname{RDX}\left(P=38.0 \mathrm{GPa}, D=8983 \mathrm{~m} \cdot \mathrm{s}^{-1}\right)$ 相当. 结果表明, DNTPP 及其大多数含能离子盐属于不敏感含 能材料.

2020 年, 张文全等 ${ }^{[86]}$ 通过在 DNPP (85)上引入二硝 基甲基基团来提高氧平衡和爆轰性能. 以水和丙酩为反 应溶剂, DNPP 与溴代丙酮在加热条件下反应，以 $86 \%$ 的收率得到化合物 97. 然后, 经硝硫混酸硝化后再与碳 酸氢钾反应, 以 $45 \%$ 的收率得到钾盐 99 . 钾盐酸化、萃 取后与一系列富氮碱进行酸碱中和反应，以 $94 \% \sim 96 \%$ 的收率制得含能离子盐 100a 100c (Scheme 30). 它们<smiles>CC(=O)Cn1nc([N+](=O)[O-])c2c1c([N+](=O)[O-])nn2CC(C)=O</smiles>

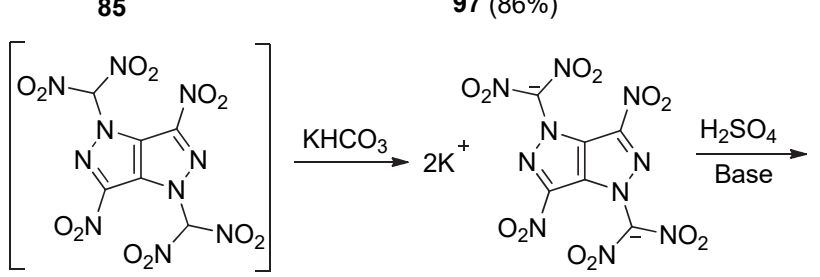
98

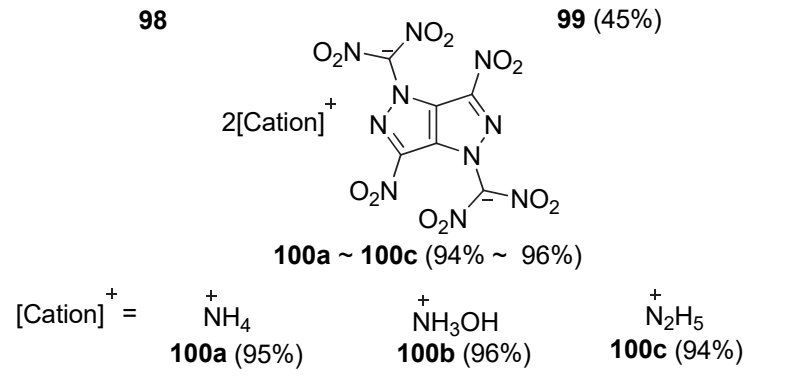

$99(45 \%)$

图式 29 3,6-二硝基-1,4-双(1H-四唑-5-基)-吡唑[4,3-c]并吡唑 含能离子盐的合成

Scheme 29 Synthesis of energetic salts based on 3,6-dinitro1,4-di(1H-tetrazol-5-yl)-pyrazolo[4,3-c]pyrazole

的密度在 $1.78(\mathbf{1 0 0 a})$ 到 $2.02(99) \mathrm{g} \cdot \mathrm{cm}^{-3}$ 之间, 热分解温 度在 113 (99)到 187 (100b) ${ }^{\circ} \mathrm{C}$ 之间. 它们的爆压在 33.0 (100a) 到 37.3 (100b) GPa 之间, 爆速在 $8677 \mathrm{~m} \cdot \mathrm{s}^{-1}$ (100a)到 $9148 \mathrm{~m} \cdot \mathrm{s}^{-1}(\mathbf{1 0 0 b}) 之$ 之间. 它们的撞击感度均小 于 $6 \mathrm{~J}$, 摩擦感度均小于 $90 \mathrm{~N}$. 这些离子盐中, 钾盐(99) 的密度最高, 达到了 $2.02 \mathrm{~g} \cdot \mathrm{cm}^{-3}$. 爆速和爆压分别为 $9018 \mathrm{~m} \cdot \mathrm{s}^{-1}$ 和 $33.6 \mathrm{GPa}$ ，与 $\mathrm{RDX}(P=38.0 \mathrm{GPa}, D=8983$ $\left.\mathrm{m} \cdot \mathrm{s}^{-1}\right)$ 相当, 但感度 $(\mathrm{IS}=2 \mathrm{~J}, \mathrm{FS}=30 \mathrm{~N})$ 高. 羟胺盐 $\mathbf{1 0 0 b}$ 综合性能最佳, 爆压和爆速分别为 $37.28 \mathrm{GPa}$ 和 9148 $\mathrm{m} \cdot \mathrm{s}^{-1}$, 优于 $\operatorname{RDX}\left(P=38.0 \mathrm{GPa}, D=8983 \mathrm{~m} \cdot \mathrm{s}^{-1}\right)$.

上述稠环吡唑离子盐及 $\mathrm{TNT} 、 \mathrm{RDX} 、 \mathrm{HMX} 、 \mathrm{CL}-20$ 的理化参数和爆轰性能见表 4 .

\subsection{1 稠环吡唑含能离子盐常用前体的合成}

稠环吡唑含能离子盐大多数是以 3,6-二硝基吡唑 $[4,3-c]$ 并吡唑(DNPP)为前体, 通过引入不同官能团对其 进行结构修饰来制备新型含能离子盐. DNPP 有两种合

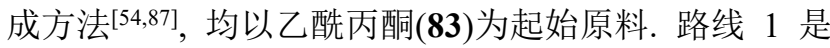
乙酰丙酮首先与水合肼反应以 $93.1 \%$ 的收率制备得到 3,5-二甲基- $1 H$-吡唑, 然后经过硝硫混酸硝化、铁粉还原 得到关键中间体 4-氨基-3,5-二甲基- $1 H$-吡唑(101). 路线 2 是乙酰丙酮 $(83)$ 首先下亚硝酸钠/盐酸作用下对两个羰 基中间体的亚甲基进行肜化，然后再一锅用水合肼进行 关环和还原制备得到化合物 101 (Scheme 31). 其中, 路 线 2 以一锅法制备 4-氨基-3,5-二甲基- $1 H$-吡唑，反应时 


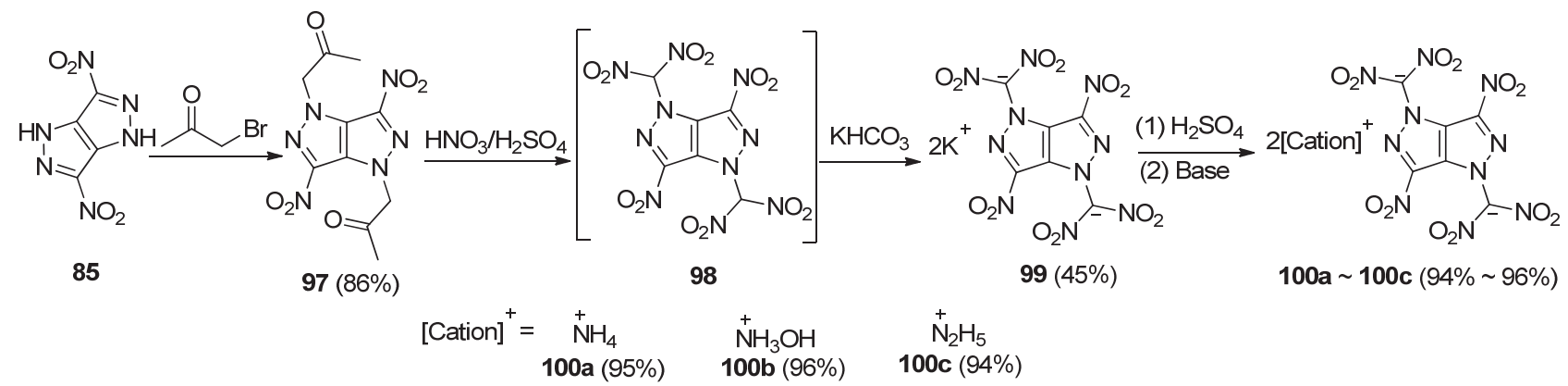

图式 30 1,4-双(二硝基甲基)-3,6-二硝基-1,4-2H-吡唑[4,3-c]并吡唑含能离子盐的合成

Scheme 30 Synthesis of energetic salts based on 1,4-bis(dinitromethyl)-3,6-dinitro-1,4-dihydropyrazolo[4,3-c]pyrazole

表 4 稠环吡唑离子盐的理化参数和爆轰性能

Table 4 Physicochemical properties and energetic properties of energetic salts based on fused pyrazole

\begin{tabular}{|c|c|c|c|c|c|c|c|c|}
\hline Compd. & $T_{\mathrm{m}}{ }^{a} /{ }^{\circ} \mathrm{C}$ & $T_{\mathrm{d}}^{b} /{ }^{\circ} \mathrm{C}$ & $d^{c} /\left(\mathrm{g} \cdot \mathrm{cm}^{-3}\right)$ & 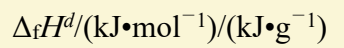 & $P^{e} / \mathrm{GPa}$ & $D^{f} /\left(\mathrm{m} \bullet \mathrm{s}^{-1}\right)$ & $\mathrm{IS}^{g} / \mathrm{J}$ & $\mathrm{FS}^{h} / \mathrm{N}$ \\
\hline $86 a$ & 160 & 328 & 1.69 & $158.5 / 0.68$ & 25.4 & 8212 & $>40$ & 360 \\
\hline $86 b$ & 174 & 327 & 1.82 & $274.2 / 1.04$ & 35.4 & 9005 & 29 & 360 \\
\hline $86 c$ & - & 247 & 1.72 & $501.0 / 1.91$ & 30.3 & 8860 & 16 & 160 \\
\hline 86d & - & 287 & 1.71 & $481.9 / 1.62$ & 24.5 & 8036 & $>40$ & 360 \\
\hline $86 e$ & - & 289 & 1.67 & $963.8 / 2.30$ & 24.6 & 8230 & $>40$ & 360 \\
\hline $86 \mathrm{~g}$ & 318 & 324 & 1.68 & $173.3 / 0.55$ & 22.5 & 7948 & $>40$ & 360 \\
\hline $86 h$ & 213 & 222 & 1.69 & $477.0 / 1.38$ & 25.6 & 8400 & $>40$ & 360 \\
\hline $86 \mathbf{i}$ & - & 209 & 1.71 & $679.6 / 1.80$ & 28.0 & 8732 & $>40$ & 360 \\
\hline $86 j$ & 208 & 215 & 1.76 & $605.5 / 2.00$ & 29.9 & 8814 & 12 & 80 \\
\hline $86 k$ & - & 238 & 1.79 & $505.6 / 1.32$ & 27.9 & 8355 & 23 & 160 \\
\hline $90 a$ & - & 144 & 1.67 & $393.1 / 1.96$ & 26.3 & 8341 & 15 & 120 \\
\hline $90 \mathrm{~b}$ & - & 112 & 1.76 & $439.4 / 2.02$ & 31.9 & 8859 & 8 & 120 \\
\hline $90 \mathrm{c}$ & - & 192 & 1.62 & $371.0 / 1.53$ & 22.5 & 7911 & 40 & 360 \\
\hline 90d & - & 181 & 1.64 & $485.3 / 1.88$ & 24.3 & 8196 & 25 & 240 \\
\hline $90 \mathrm{e}$ & - & 188 & 1.74 & $916.4 / 2.71$ & 27.5 & 8519 & 15 & 160 \\
\hline 93a & - & 170 & 1.88 & $531.2 / 1.38$ & 41.3 & 9495 & 7 & 120 \\
\hline $93 \mathrm{~b}$ & - & 181 & 1.81 & $423.1 / 1.20$ & 35.9 & 8977 & 10 & 120 \\
\hline $93 \mathrm{c}$ & - & 174 & 1.85 & 738.9/1.93 & 39.5 & 9399 & 5 & 60 \\
\hline 93d & - & 190 & 1.68 & $454.7 / 1.04$ & 26.9 & 8295 & 35 & 360 \\
\hline $93 e$ & - & 141 & 1.70 & $1144.8 / 2.17$ & 30.8 & 8884 & 10 & 80 \\
\hline $93 f$ & - & 153 & 1.71 & $692.9 / 1.49$ & 29.3 & 8612 & 30 & 360 \\
\hline $93 \mathrm{~g}$ & - & 163 & 1.78 & $1683.3 / 3.25$ & 36.0 & 9166 & 5 & 60 \\
\hline 93h & - & 203 & 1.83 & $1599.5 / 2.56$ & 33.1 & 8993 & 10 & 120 \\
\hline $96 a$ & - & 178 & 1.61 & $1062.2 / 2.65$ & 26.0 & 8237 & 27.5 & 324 \\
\hline $96 b$ & - & 221 & 1.75 & $1223.0 / 3.07$ & 31.3 & 9082 & 12 & 144 \\
\hline $96 \mathrm{c}$ & - & 280 & 1.69 & $916.8 / 2.49$ & 26.2 & 8404 & 19 & $>360$ \\
\hline 96d & - & 299 & 1.62 & $926.9 / 2.05$ & 22.4 & 8023 & $>60$ & $>360$ \\
\hline $96 \mathrm{e}$ & - & 255 & 1.64 & $1143.3 / 2.37$ & 24.9 & 8396 & 35 & $>360$ \\
\hline $100 \mathrm{a}$ & - & 169 & 1.78 & $188.9 / 0.43$ & 33.0 & 8677 & 3 & 90 \\
\hline $100 \mathrm{~b}$ & - & 187 & 1.86 & $288.8 / 0.61$ & 37.3 & 9148 & 2 & 20 \\
\hline $100 \mathrm{c}$ & - & 165 & 1.81 & $497.5 / 1.06$ & 36.1 & 8984 & 5 & 60 \\
\hline $\mathrm{TNT}^{i}$ & 81 & 290 & 1.65 & $-55.5 /-0.24$ & 23.5 & 7459 & 15 & 353 \\
\hline $\mathrm{RDX}^{i}$ & 205 & 210 & 1.81 & $86.3 / 0.39$ & 38.0 & 8983 & 7.5 & 120 \\
\hline $\mathrm{HMX}^{i}$ & 275 & 279 & 1.90 & $116.1 / 0.39$ & 41.5 & 9221 & 7 & 112 \\
\hline CL-20 ${ }^{i}$ & - & 215 & 2.03 & $365.4 / 0.83$ & 46.7 & 9455 & 4 & 48 \\
\hline
\end{tabular}

${ }^{a}$ Melting point. ${ }^{b}$ Decomposition temperature. ${ }^{c}$ Density. ${ }^{d}$ Calculated molar enthalpy of formation. ${ }^{e}$ Detonation pressure. ${ }^{f}$ Detonation velocity. ${ }^{g}$ Impact sensitivity

${ }^{h}$ Friction sensitivity. ${ }^{i}$ Ref. [4]. 

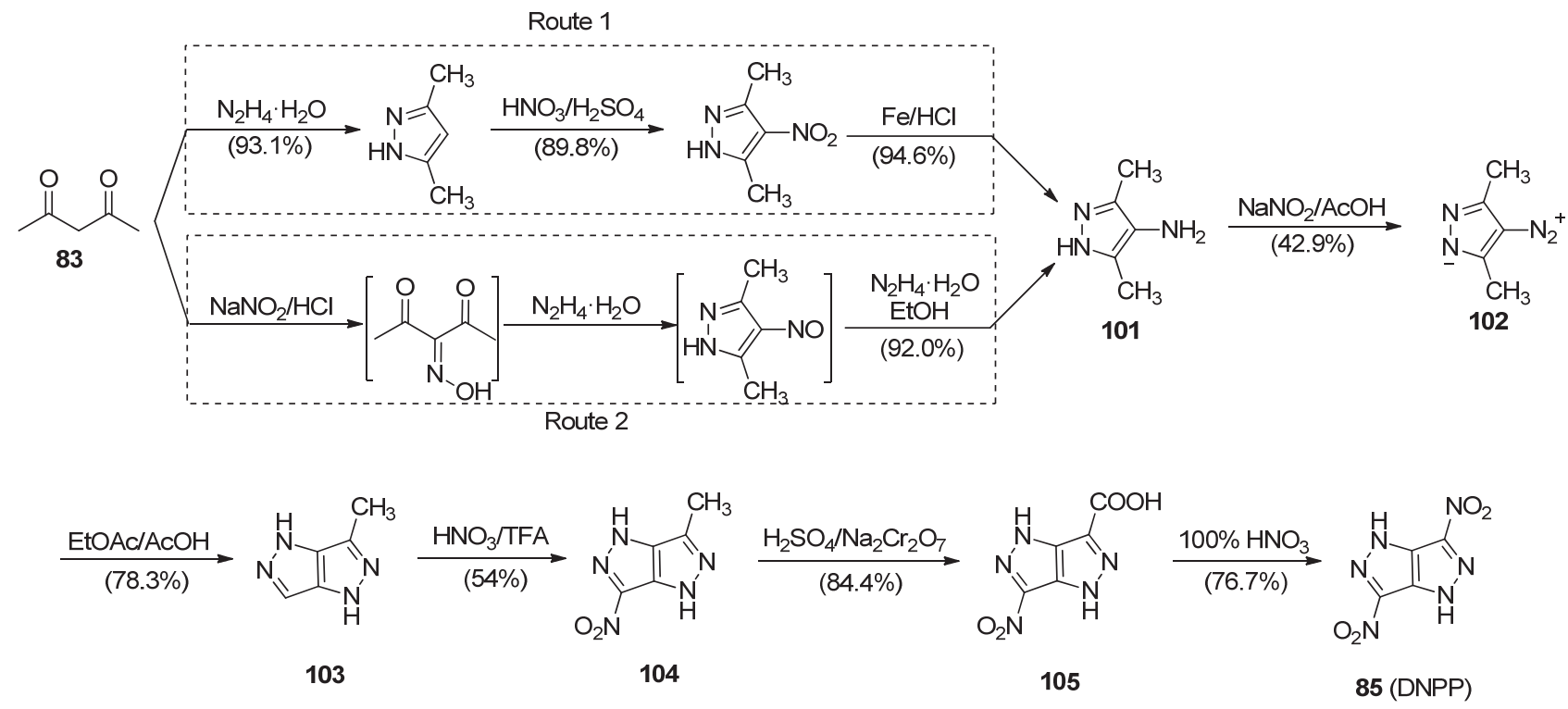

图式 31 DNPP 的不同合成方法

Scheme 31 Different synthetic methods of DNPP

间短且收率高(路线 1: 79.1\%; 路线 2: $92.0 \%$ ). 化合物 101 与亚硝酸钠与乙酸反应以 $42.9 \%$ 的收率生成重氮内 盐(102), 化合物 102 在醋酸的催化下, 在乙酸乙酯中完 成关环以 $78.3 \%$ 的收率得到化合物 $\mathbf{1 0 3}$, 再用 $\mathrm{HNO}_{3}$ 三 三 氟乙酸(TFA)硝化体系对其进行硝化, 以 $54 \%$ 的收率得 到化合物 104, $\mathrm{Na}_{2} \mathrm{Cr}_{2} \mathrm{O}_{7}$ 作为氧化剂对化合物 104 进行 氧化, 以 $84.4 \%$ 的收率得到化合物 $\mathbf{1 0 5}$, 最后用 $100 \%$ 的 发烟硝酸硝化化合物 105 得到 3,6-二硝基吡坐 [4,3- $c$ 并 吡唑 $(\mathbf{8 5}, \mathrm{DNPP})$.

\subsection{2 稠环吡唑含能离子盐合成中常用反应的反应} 机理

3,6-二硝基吡唑 $[4,3-c]$ 并吡唑(DNPP) ${ }^{[60]}$ 合成路线 1 中中间体 101 制备的反应机理是: 乙酰丙酮与水合肼依 次发生加成、脱水缩合、重排反应, 生成 3,5-二甲基吡 唑. 硝硫混酸产生的 $\mathrm{NO}_{2}{ }^{+}$进攻 3,5-二甲基吡唑 4 位上的
碳发生亲电取代反应, 得到 4-硝基-3,5-二甲基吡唑. 最 后，以铁为还原剂，在酸性条件下将 4-硝基-3,5-二甲基 吡唑上的硝基还原成氨基得到化合物 101 (Scheme 32).

3,6-二硝基吡唑 $[4,3-c]$ 并吡唑(DNPP) ${ }^{[60,88]}$ 合成路线 2 中中间体 101 制备的反应机理是: 乙酰丙酮在亚硝酸 钠和盐酸的作用下生成 3-肜基戊二酮(106), 化合物 106 与肼发生加成反应得到中间体 107, 中间体 107 不稳定, 易脱去两分子的水得到中间体 108, 中间体 108 发生分 子内的重排得到 4-亚硝基-3,5-二甲基吡唑(109), 接着被 肼还原为偶氮化合物 $\mathbf{1 1 0}$, 然后在回流条件下, 脱去一 分子的氮气得到目标化合物 4-氨基-3,5-二甲基吡唑 (101) (Scheme 33).

由中间体 101 制备 DNPP 的反应过程: 4-氨基-3,5二甲基吡唑(101)与重氮化试剂结合, 发生一系列质子 转移, 生成重氮盐 102 . 乙酸作为催化剂, 与重氮盐反<smiles>CC(=O)CC(=O)CC(N)=O</smiles>

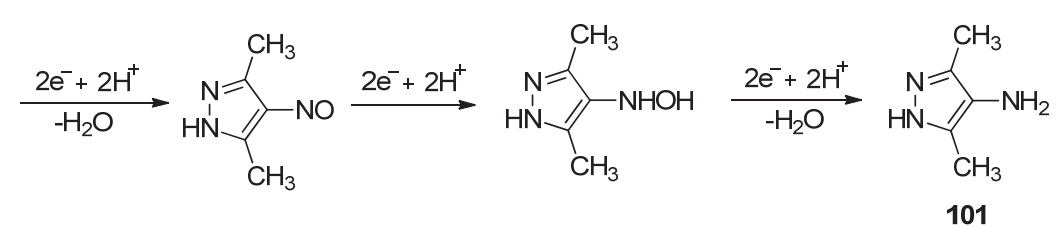

图式 32 路线 1 的反应机理

Scheme 32 Reaction mechanism of route 1 


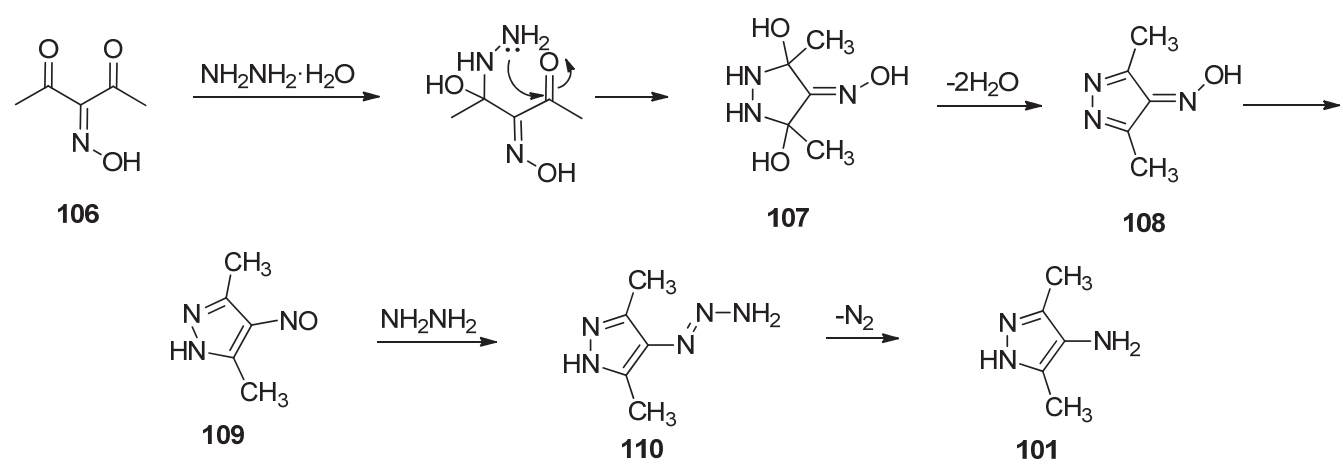

图式 33 路线 2 的反应机理

Scheme 33 Reaction mechanism of route 2

应得到化合物 111. 然后, 乙酸根与重氮盐反应得到 112,112 发生分子内关环, 脱除一分子乙酸, 得到化合 物 114, 其经分子内重排得到化合物 103. 再用 $\mathrm{HNO}_{3}$ /TFA 硝化体系对 103 进行硝化得到化合物 104, 再氧化得到化合物 105 . 最后, 经过脱羒硝化制备得到 3,6-二硝基吡唑 [4,3-c]并吡唑(85, DNPP, Scheme 34).

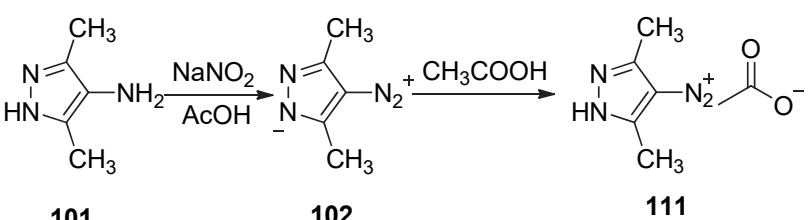<smiles>C=C(C)ONNc1c(C)nn(C(C)(C)C)c1C</smiles>

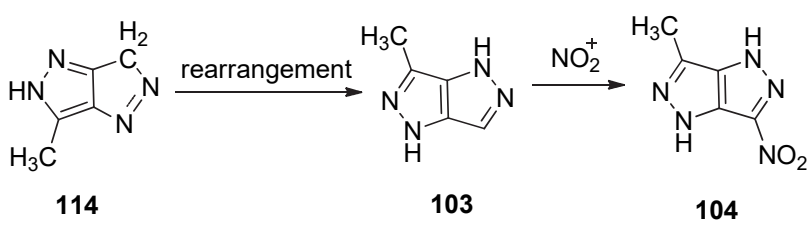<smiles>O=C(O)c1n[nH]c2c([N+](=O)[O-])[nH]c([N+](=O)[O-])c12</smiles>

图式 34 由化合物 101 制备 DNPP 的反应过程

Scheme 34 Synthesis of DNPP from compound 101

\section{2 结论与展望}

含能化合物被广泛应用于推进剂、炸药和烟火药中, 随着科技发展和社会进步, 含能材料领域对含能化合物
提出了更高的要求，需要开发综合性能优良即密度高、 热稳定性好、感度低、能量高、绿色、合成成本低的新 型含能化合物. 但是, 含能化合物的能量和感度之间往 往存在相互矛盾的关系，因此，研制综合性能优良的新 型含能化合物是一个极具挑战的课题，受到了世界各国 科学家的广泛关注. 由于吡唑有多个可修饰位点且吡唑 含能化合物通常具有较低的感度，因此，吡唑环被大量 应用于含能离子盐的设计与合成中. 本文综述了近年来 吡唑含能离子盐的合成研究进展, 共包括 33 个系列吡 唑含能离子盐, 对它们的合成方法和性能进行了评述.

从爆轰性能 $\left(P \geqslant 9000 \mathrm{~m} \bullet \mathrm{s}^{-1}\right)$ 和密度 $(d \geqslant 1.80 \mathrm{~g} \cdot$ $\mathrm{cm}^{-3}$ )角度看, 本文所综述的吡唑含能离子盐中单环吡 唑含能离子盐 $15 \mathrm{a}$, 联环吡唑含能离子盐 $44 \mathrm{i}, 55 \mathrm{~b}$ 和 $82 \mathrm{f}$, 以及稠环吡唑含能离子盐 $86 \mathrm{~b}, 93 \mathrm{a}$ 和 $100 \mathrm{~b}$ 是潜在的 RDX 替代物. 进一步考虑机械感度(IS $<7 \mathrm{~J} ; \mathrm{FS}<120$ $\mathrm{N})$, 本文所综述的吡唑含能离子盐中联环吡唑含能离子 盐 44i 和 $55 \mathrm{~b}$ 以及稠环吡唑含能离子盐 $86 \mathrm{~b}$ 和 $93 \mathrm{a}$ 是潜 在的 RDX 替代物. 若再进一步考虑热分解温度 $\left(T_{\mathrm{d}}>\right.$ $200{ }^{\circ} \mathrm{C}$ ), 仅有稠环吡唑含能离子盐 $86 \mathrm{~b}$ 有望作为 $\mathrm{RDX}$ 替代物(图 4). 但是化合物 86b 的合成路线太长, 因此, 若想 86b 真正用作 RDX 的替代物还需要开展合成路线 的重新设计，开发出路线短、成本低、易于放大的合成 工艺.

总体来看，基于吡唑环来设计并合成新型含能化合 物特别是离子盐型含能化合物是一个非常好的研究方 向，未来的工作可以从三个方面开展研究：(1)从含能骨 架、官能团衍生化、阴阳离子组合等角度，继续设计并 合成具有全新结构的吡唑含能离子盐, 实现吡唑含能离 子盐性能上的突破; (2)基于已经开发的吡唑含能离子 盐，开展合成路线、合成工艺开发，实现小批规模的制 备; (3)选择综合性能较优的吡唑含能离子盐, 开展在推 进剂及炸药等方面的应用研究. 


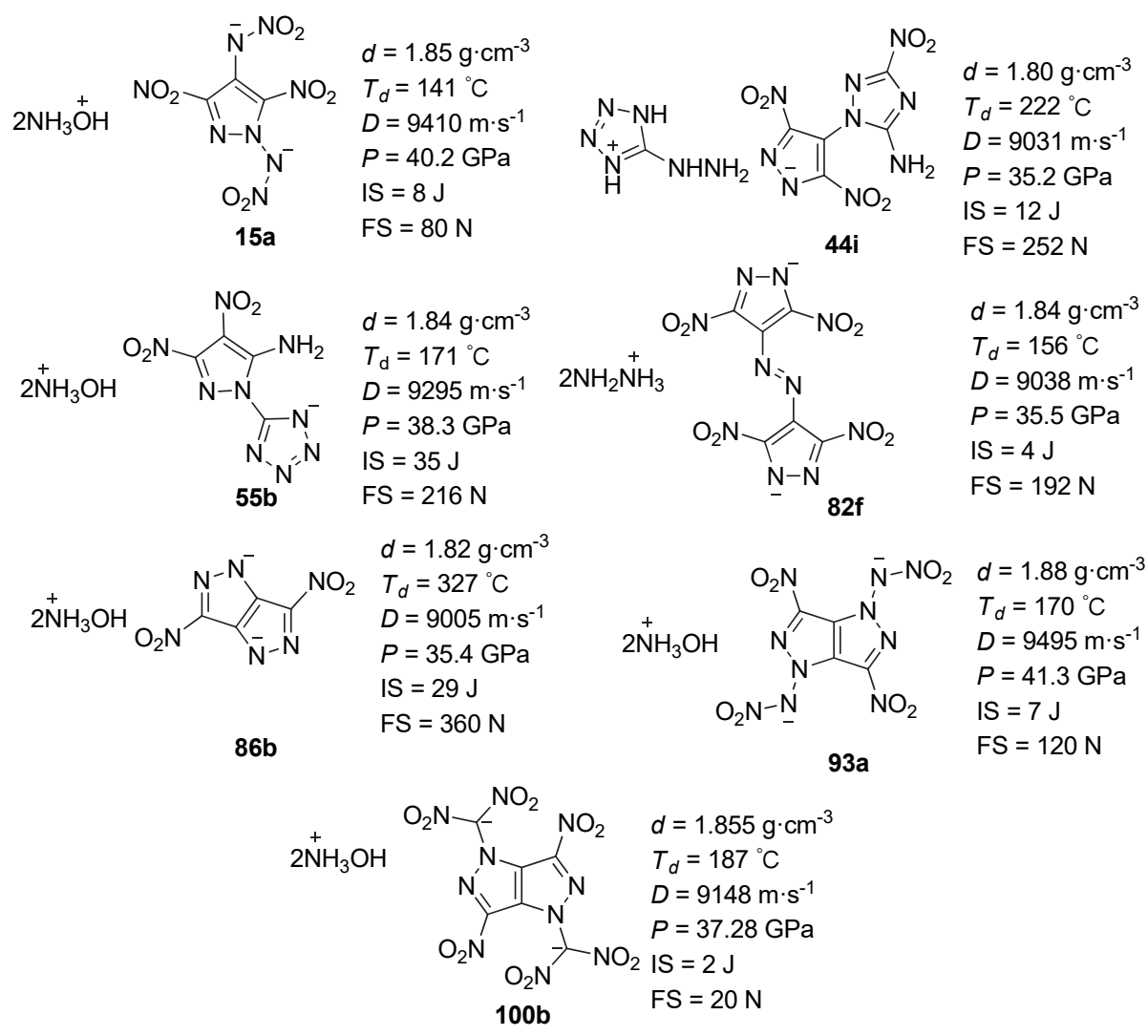

图 4 综合性能较好的吡唑含能离子盐结构及其性能

Figure 4 Structures and performances of pyrazole energetic salts with better comprehensive performances

\section{References}

[1] Yang, G.-C.; Li, X.-D. Chin. J. Energ. Mater. 2018, 26, 1000 (in Chinese). (杨光成, 李小东, 含能材料, 2018, 26, 1000.)

[2] Lu, M. Chin. J. Energ. Mater. 2018, 26, 373 (in Chinese). (陆明, 含能材料, 2018, 26, 373.)

[3] Huo, H.; Zhang, J.; Dong, J.; Zhai, L.; Guoy, T.; Wang, Z.; Bi, F.; Wang, B. RSC Adv. 2020, 10, 11816.

[4] Fischer, N.; Fischer, D.; Klapötke, T. M.; Piercey, D. G.; Stierstorfer, J. J. Mater. Chem. 2012, 22, 20418.

[5] Huang, X.-C.; Guo, T.; Liu, M.; Wang, Z.-J.; Qiu, S.-J.; Ge, Z.-X. Chin. J. Energ. Mater. 2015, 23, 291 (in Chinese). (黄晓川, 郭涛, 刘敏, 王子俊, 邱少君, 葛忠学, 含能材料, 2015, 23, 291.)

[6] Trache, D.; Klapötke, T. M.; Maiz, L.; Abd-Elghany, M..; DeLuca, L. T. Green Chem. 2017, 19, 4711.

[7] Oommen, C.; Jain, S. R. J. Hazard. Mater. 1999, 67, 253.

[8] Jos, J.; Mathew, S. Crit. Rev. Solid State Mater. Sci. 2017, 42, 470.

[9] Venkatachalam, S.; Santhosh, G.; Ninan, K. N. Propellants, Explos., Pyrotech. 2004, 29, 178.

[10] Schoyer, H. F. R.; Welland-Veltmans, W. H. M.; Louwers, J.; Korting, P. A. O. G.; Heijden, A. E. D. M.; Keizers, H. L. J.; Berg, R. P. J. Propul. Power 2002, 18, 131.

[11] Freudenmann, D.; Ciezki, H. K. Propellants, Explos., Pyrotech. 2019, 44, 1084.

[12] Drake, G.; Hawkins, T.; Brand, A.; Hall, L.; Mckay, M. Propellants, Explos., Pyrotech. 2003, 28, 174.

[13] Singh, R. P.; Verma, R. D.; Shreeve, J. M. Angew. Chem., Int. Ed. 2006, 45, 3584 .

[14] Gao, H.; Shreeve, J. M. Chem. Rev. 2011, 111, 7377.

[15] Gao, H.; Zhang, Q.; Shreeve, J. M. J. Mater. Chem. A 2020, 8, 4193.

[16] He, P.; Zhang, J. G.; Yin, X.; Wu, J. T.; Wu, L.; Zhou, Z. N.; Zhang,
T. L. Chem.-Eur. J. 2016, 22, 7670.

[17] Zhang, Y.; Gao, H.; Joo, Y. H.; Shreeve, J. M. Angew Chem., Int Ed. 2011, 50, 9554.

[18] Zhou, Y.-F.; Wang, T.; Wang, Q.-X.; Gao, H.-X. Chin. J. Energ. Mater. 2018, 26, 967 (in Chinese). (周奕霏，汪涛，王秋晓，高海翔，含能材料, 2018, 26, 967.)

[19] Wang, R.; Xu, H.; Guo, Y.; Sa, R.; Shreeve, J. M. J. Am. Chem. Soc 2010, 132, 11904.

[20] Dippold, A. A.; Klapötke, T. M. J. Am. Chem. Soc. 2013, 135, 9931.

[21] Chen, S.; Liu, Y.; Feng, Y.; Yang, X.; Zhang, Q. Chem. Commun. 2020, 56, 1493.

[22] Yang, F.; Zhang, P.; Zhou, X.; Lin, Q.; Wang, P.; Lu, M. Cryst. Growth Des. 2020, 20, 3737.

[23] Zhao, G.; Kumar, D.; Yin, P.; He, C.; Imler, G. H.; Parrish, D. A.; Shreeve, J. M. Org. Lett. 2019, 21, 1073.

[24] Zhao, T.-X.; Li, L.; Dong, Z.; Zhang, Y.; Zhang, G.-Q.; Huang, M.; Li, H.-B. Chin. J. Org. Chem. 2014, 34, 304 (in Chinese). (赵廷兴, 李磊, 董战, 张勇, 张光全, 黄明, 李鸿波, 有机化学, 2014, 34, 304.)

[25] Fustero, S.; Sánchez-Roselló, M.; Barrio, P.; Simón-Fuentes, A. Chem. Rev. 2011, 111, 6984.

[26] Zheng, K.; Iqbal, S.; Hernandez, P.; Park, H.; LoGrasso, P. V.; Feng, Y. J. Med. Chem. 2014, 57, 10013 .

[27] Urich, R.; Grimaldi, R.; Luksch, T.; Frearson, J. A.; Brenk, R.; Wyatt, P. G. J. Med. Chem. 2014, 57, 75369.

[28] Lahm, G. P.; Cordova, D.; Barry, J. D. Bioorg. Med. Chem. 2009, $17,4127$.

[29] Weston, C. E.; Richardson, R. D.; Haycock, P. R.; White, A. J. P.; Fuchter, M. J. J. Am. Chem. Soc. 2014, 136, 11878.

[30] Hervé, G.; Roussel, C.; Graindorge, H. Angew. Chem., Int. Ed. 2010, 49, 3177.

[31] Tang, Y.; Kumar, D.; Shreeve, J. M. J. Am. Chem. Soc. 2017, 139, 13684.

[32] Kumar, D.; He, C.; Mitchell, L. A.; Parrish, D. A.; Shreeve, J. M. J. 
Mater. Chem. A 2016, 4, 9220.

[33] Yin, P.; Zhang, J.; He, C.; Parrish, D. A.; Shreeve, J. M. J. Mater. Chem. A. 2014, 2, 3200

[34] Huang, H.; Shi, Y.; Li, H.; Li, H.; Pang, A.; Yang, J. Org. Lett. 2020, 22, 5866

[35] Drukenmüller, I. E.; Klapötke, T. M.; Morgenstern, Y.; Rusan, M.; Stierstorfer. J. Z. Anorg. Allg. Chem. 2014, 640, 2139.

[36] Jiang, T.; Zhang, X.-Y.; Jing, M.; Shu, Y.-J.; Wang, J. Chin. J. Energ. Mater. 2014, 222, 654 (in Chinese). (蒋涛, 张晓玉, 景梅, 舒远杰, 王军, 含能材料, 2014, 222, 654.)

[37] Zhao, X. X.; Qi, C.; Zhang, L. B. Molecules 2014, 19, 896.

[38] Politzer, P.; Lane, P.; Murray, J. S. Mol. Phys. 2013, 112, 719.

[39] Wu, J.-P.; Cao, D.-L.; Wang, J.-L.; Liu, Y.; Li, Y.-X. Chin. J. Energ. Mater. 2016, 24, 1121 (in Chinese).

(吴军鹏, 曹端林, 王建龙, 刘洋, 李永祥, 含能材料, 2016, 24, 1121.)

[40] Wang, W.-J.; Li, H.; Pan, R.-M.; Zhu, W.-H. Chin. J. Org. Chem. 2019, 39, 1362 (in Chinese).

(王万军, 李欢, 潘仁明, 朱卫华, 有机化学, 2019, 39, 1362.)

[41] Zhang, Y. Q.; Guo Y.; Joo, Y. H. Chem.-Eur. J. 2010, 116, 10778.

[42] Zhang, Y. Q.; Parrish, D. A.; Shreeve, J. M. J. Mater. Chem. 2012, 22,12659

[43] Schmidt, R. D.; Lee, G. S.; Pagoria, P. F.; Mitchell, A. R. J. Heterocycl. Chem. 2001,38,1227.

[44] Zhang, Y. Q.; Parrish, D. A.; Shreeve, J. M. Chem.-Eur. J. 2012, 18, 987.

[45] Yin, P.; Parrish, D. A.; Shreeve, J. M. J. Am. Chem. Soc. 2015, 1137, 4778.

[46] Deng, M.-C.; Wang, Y.; Zhang, W.-Q.; Zhang, Q.-H. Chin. J. Energ. Mater. 2017, 25, 646 (in Chinese) (邓沐聪，王毅，张文全，张庆华，含能材料, 2017, 25, 646.)

[47] Yin, P.; Mitchell, L. A.; Parrish, D. A. Chem.-Asian J. 2017, 112, 378.

[48] Bölter, M. F.; Klapötke, T. M.; Kustermann, T.; Lenz, T.; Stierstorfer, J. Eur. J. Inorg. Chem. 2018, 37, 4125.

[49] Zhang, Y. Y.; Li, Y. N. Dalton Trans. 2019, 448, 1524.

[50] Zhang, Y. Y.; Li, Y. N.; Yu, T.; Liu, Y. Z.; Chen, S. P.; Ge, Z. X.; Sun, C. H.; Pang, S. P. ACS Omega 2019, 44, 19011.

[51] Lei, C. J.; Yang, H. W.; Cheng, G. B. Dalton Trans. 2020, 49, 1660.

[52] Hervé, G.; Roussel, C.; Graindorge, H. Angew. Chem., Int. Ed. 2010, 122, 3177.

[53] Dalinger, I. L.; Vatsadze, I. A.; Shkineva, T. K.; Popova, G. P.; Shevelev, S. A. Mendeleev Commun. 2010, 20, 253.

[54] Ravi, P.; Tewari, S. P. Catal. Commun. 2012, 19, 37.

[55] Ravi, P.; Gore, G. M.; Tewari, S. P.; Sikder, A, K. J. Heterocycl. Chem. 2013, 50, 1322.

[56] Zhao, X. X.; Zhang, J. C.; Li, S. H.; Yang, Q. P.; Liu, Y.; C.; Pang, S. P. Org. Process Res. Dev. 2014, 18, 886.

[57] Ravi, P.; Gore, G. M.; Sikder, A. K.; Tewari, S. P. Synth. Commun. 2012, 42, 3463.

[58] Bölter, M. F.; Harter, A.; Klapötke, T. M.; Stierstorfer, J. ChemPlusChem 2018, 83, 804.

[59] Janssen, J. W. A. M.; Habraken, C. L. J. Org. Chem. 1971, 36, 3081.

[60] Janssen, J. W. A. M.; Koeners, H. J.; Kruse, C. G.; Habraken, C. L. J. Org. Chem.1973, 38, 1777.

[61] Makosza, M.; Winiarski, J. Acc. Chem. Res. 1987, 20, 282.

[62] Li, C.; Liang, L. X.; Wang, K.; Bian, C. M.; Zhang, J.; Zhou, Z. M.
J. Mater. Chem. A 2014, 22, 18097.

[63] Li, C.; Zhang, M.; Chen, Q. S.; Li, Y. Y.; Gao, H. Q.; Fu, W.; Zhou, Z. M. Dalton Trans. 2016, 445, 17956.

[64] Kumar, D.; Imler, G. H.; Parrish, D. A.; Shreeve, J. M. Chem.-Eur. J. 2017, 23, 7876.

[65] Fu, W.; Zhao, B. J.; Zhang, M.; Li, C.; Gao, H. Q.; Zhang, J.; Zhou, Z. M. J. Mater. Chem. A 2017, 5, 5044.

[66] Tang, Y. X.; Ma, J. C.; Imler, G. H.; Parrish, D. A.; Shreeve, J. M. Dalton Trans. 2019, 48, 14490 .

[67] Sheremetev, A. B.; Yudin, I. L.; Palysaeva, N. V.; Suponitsky. K. Y. J. Heterocycl. Chem. 2012, 49, 394.

[68] Tang, Y. X.; He, C. L.; Imler, G. H.; Parrish, D. A.; Shreeve, J. M. J. Mater. Chem. A 2018, 6, 5136.

[69] Xu, M. X.; Cheng, G. B.; Xiong, H. L.; Wang, B. H.; Ju, X. H.; Yang, H. W. New J. Chem. 2019, 43, 11157.

[70] Benz, M.; Klapötke, T. M.; Stierstorfer, J. Z. Anorg. Allg. Chem. 2020, 646, 1 .

[71] Gospodinov, I.; Domasevitch, K. V.; Unger, C. C.; Klapötke, T. M. Cryst. Growth Des. 2020, $20,755$.

[72] Ma, Q.; Zhang, G. J.; Li, J.; Zhang, Z. Q.; Lu, H. C.; Liao, L. Y.; Fan, G. J.; Nie, F. Chem. Eng. J. 2020, 379, 1.

[73] Tang, Y.; He, C.; Mitchell, L. A.; Parrish, D. A.; Shreeve, J. M. Angew. Chem., Int. Ed. 2016, 55, 5565.

[74] Zhang, M.; Fu, W.; Li, C.; Gao, H. Q.; Tang, L. W.; Zhou, Z. M. Eur. J. Inorg. Chem. 2017, 22, 2883.

[75] Schulze, M. C.; Scott, B. L.; Chavez, D. E. J. Mater. Chem. A 2015 , 3, 17963.

[76] Klenov, M. S.; Guskov, A. A.; Anikin, O. V.; Churakov, A. M.; Strelenko, Y. A.; Fedyanin, I. V.; Lyssenko, K. A.; Tartakovsky, V. A. Angew. Chem., Int. Ed. 2016, 55, 11472.

[77] Chavez, E. E.; Parrish, D. A.; Mitchell, L.; Imler, G. H. Angew. Chem., Int. Ed. 2017, 56, 3575.

[78] Yin, P.; Zhang, J.; Imler, G. H.; Parrish, D. A.; Shreeve, J. M. Angew. Chem., Int. Ed. 2017, 56, 8834.

[79] Zhang, J.; Yin, P.; Mitchell, L. A.; Parrish, D. A.; Shreeve, J. M. J. Mater. Chem. A 2016, 4, 7430.

[80] Shevelev, S. A.; Dalinger, I. L.; Shkineva, T. K.; Gulevskaya, B. I. U. V. I.; Kanishichev, M. I. Russ. Chem. Bull. 1993. 42, 1063.

[81] Zhang, J. H.; Parrish, D. A.; Shreeve, J. M. Chem.-Asian J. 2014, 99, 2953.

[82] Yin, P.; He, C. L.; Shreeve, J. M. J. Mater. Chem. A 2016, 4, 1514.

[83] Yin, P.; Zhang, J. H.; Mitchell, L. A.; Parrish, D. A.; Shreeve, J. M. Angew. Chem., Int. Ed. 2016, 555, 12895.

[84] Li, Y. N.; Hu, J. J.; Chang, P.; Chen, T.; Zhang, H. W.; Wang, B. Chin. J. Expl. Propell. 2019, 42, 341 (in Chinese) (李亚南, 胡建建, 常佩, 陈涛, 张红武, 王涁, 火炸药学报, 2019, 42, 341.)

[85] Xia, H. L.; Zhang, W. Q.; Jin, Y. H. ACS Appl. Mater. Interfaces 2019, 111, 45914.

[86] Zhang, W. Q.; Xia, H. L.; Yu, R. J.; Zhang, J. H.; Wang, K. C.; Zhang, Q. H. Propellants, Explos., Pyrotech. 2020, 45, 546.

[87] Luo, Y.-F.; Ge, Z.-X.; Wang, B.-Z.; Zhang, H.-H; Liu, X. Chin. J. Energ. Mater. 2007, 15, 205 (in Chinese) (罗义芬, 葛忠学, 王伯周, 张海昊, 刘荇, 含能材料, 2007, 15, 205.)

[88] Cameron, M.; Gowenlock, B. G.; Boyd, A. F. J. Chem. Soc., Perkin Trans. 2 1996, 11, 2271 